\title{
A light-gated transcriptional recorder for detecting cell-cell contacts
}

Kelvin F. Cho ${ }^{1,2}$, Shawn M. Gillespie ${ }^{1,3}$, Nicholas A. Kalogriopoulos ${ }^{2}$ Michael A. Quezada $^{3}$, Martin Jacko ${ }^{4}$, Michelle Monje ${ }^{3,5-8}$, and Alice Y. Ting ${ }^{2,9-11^{*}}$

${ }^{1}$ Cancer Biology Program, Stanford University, Stanford, CA, USA

${ }^{2}$ Department of Genetics, Stanford University, Stanford, CA, USA

${ }^{3}$ Department of Neurology and Neurological Sciences, Stanford University, Stanford,

CA, USA

${ }^{4}$ BridgeBio, Palo Alto, CA, USA

${ }^{5}$ Department of Pathology, Stanford University, Stanford, CA, USA

${ }^{6}$ Department of Pediatrics, Stanford University, Stanford, CA, USA

${ }^{7}$ Department of Neurosurgery, Stanford University, Stanford, CA, USA

${ }^{8}$ Howard Hughes Medical Institute, Stanford University, Stanford, CA, USA

${ }^{9}$ Department of Biology, Stanford University, Stanford, CA, USA

${ }^{10}$ Department of Chemistry, Stanford University, Stanford, CA, USA

${ }^{11}$ Chan Zuckerberg Biohub, San Francisco, CA, USA

*Correspondence should be addressed to Alice Y. Ting (ayting@stanford.edu) 


\begin{abstract}
Technologies for detecting cell-cell contacts are powerful tools for studying a wide range of biological processes, from neuronal signaling to cancer-immune interactions within the tumor microenvironment. Here we report TRACC, a GPCR-based transcriptional recorder of cellular contacts, which converts contact events into stable transgene expression. TRACC is derived from our previous protein-protein interaction recorders, SPARK (Kim et al., 2017) and SPARK2 (Kim et al., 2019). TRACC incorporates light gating via the LOV domain, which provides user-defined temporal control of tool activation and reduces background. We show that TRACC detects cellcell contacts with high specificity and sensitivity in mammalian cell culture and that it can be used to interrogate interactions between neurons and glioma, a form of brain cancer.
\end{abstract}

\title{
Introduction
}

Cell-cell interactions are integral to maintaining cellular and organismal homeostasis; signaling that occurs from direct physical cellular contacts mediate a diverse range of biological processes, including embryonic development, neuronal signaling, and immune-cancer interactions (Armingol et al., 2021; Dustin, 2014; Zhang and Liu, 2019). Consequently, several molecular tools have been developed to visualize and detect cell-cell interactions between different cell populations. Technologies based on enzymatic labeling strategies result in chemical labeling at contact sites, which allows for direct visualization. For example, LIPSTIC uses sortase A to catalyze labeling on the cell surface of interacting cells and has been applied to study $\mathrm{T}$ cell interactions (Pasqual et al., 2018). Similarly, the biotin ligase BirA and lipoic acid ligase LplA have been engineered for labeling across synaptic contacts to visualize neuronal synapses (Liu et al., 2013). Split forms of horseradish peroxidase (HRP) (Martell et al., 2016) and the biotin ligase TurboID (Cho et al., 
2020; Takano et al., 2020) have also been engineered to perform both extracellular and intracellular labeling at cell-cell contact sites; mGRASP (Kim et al., 2012) and SynView (Tsetsenis et al., 2014) reconstitute GFP across neuronal synapses.

While direct visualization of cellular contacts is useful, it is often desirable to also highlight the entire contacting cell, so that cell anatomy, transcriptomic signature, and functional properties can be further characterized. Various tools have been engineered that result in the release of an orthogonal transcription factor in the receiver cell after contact with a sender cell, allowing for a range of user-desired outputs. These include the Notch-based systems synNotch (Morsut et al., 2016) and TRACT (Huang et al., 2017), and the GPCR-based system trans-Tango (Talay et al., 2017). Other approaches involving trans-cellular uptake of protein cargo have also been developed; in BAcTrace, the botulinum neurotoxin is transferred to the receiver cell, which also results in proteolytic release of a transcription factor (Cachero et al., 2020), while in G-baToN, a fluorescent protein is transferred, which labels the receiver cell (Tang et al., 2020). These aforementioned tools (TRACT, trans-Tango, and BAcTrace) have not yet been tested in mammalian systems and lack temporal gating, which can provide temporal specificity and reduce background signal (Kim et al., 2017).

Here we describe a different and complementary technology for transcriptional recording of cellcell contacts. In TRACC (Transcriptional Readout Activated by Cell-cell Contacts), a GPCR in the receiver cell is activated upon interaction with a ligand expressed on sender cells, resulting in the release of a transcription factor, which allows for versatile outputs. By incorporating an engineered light-oxygen-voltage-sensing (LOV) domain, the tool becomes light-gated, and tool 
activation requires both cell contact and exogenous blue light, restricting activation only to userdefined time windows. We show that TRACC can detect cellular contacts with high specificity and sensitivity in HEK293T culture. We further demonstrate its utility by extending to neuronal cultures and assaying interactions in co-culture between glioma cells and neurons.

\section{Results}

\section{Design and development of TRACC.}

To design TRACC, we built upon our previously published tool SPARK, which detects proteinprotein interactions with transcriptional readout (Kim et al., 2019, 2017). TRACC is comprised of four components, as shown in Figure 1A-B. On the sender cell, a ligand is presented on the cell surface by fusion to pre-mGRASP, a construct that contains the transmembrane domain of CD4 and the intracellular domain of the pre-synaptic protein neurexin (Kim et al., 2012). On the receiver cell, a corresponding GPCR is expressed and fused to a LOV domain, a TEV cleavage site (TEVcs; ENLYFQM), and a transcription factor (TF). Additionally, the receiver cell expresses arrestin fused to the TEV protease (TEVp) and a reporter construct of interest. Upon cell-cell contact, the ligand on the sender cell activates the GPCR on the receiver cell, resulting in recruitment of arrestin-TEVp. However, in the absence of light, the LOV domain cages the TEVcs, rendering it inaccessible to the TEVp. With the addition of exogenous blue light, the LOV domain uncages, resulting in subsequent cleavage and release of a transcription factor and reporter activation. Thus, TRACC is designed as an "AND" logic gate, simultaneously requiring contact with a sender cell and exogenous blue light. 
To first test our design in HEK293T cells, we utilized eLOV, a previously engineered LOV domain that has improved light caging (Wang et al., 2017), and the orthogonal Gal4-UAS transcription factor system. To ensure that TRACC would be orthogonal for eventual applications in neuroscience, we selected 6 GPCR-ligand pairs that are not expressed or lowly-expressed in the brain according to the GTEx database (Lonsdale et al., 2013). These are CCR3-CCL13, CCR6CCL20, CCR6-CCL19, GHRHR-GHRH, GNRHR-GnRH, and GCGR-GCG, the last of which was utilized in trans-Tango (Talay et al., 2017). GPCR-ligand pairs were cloned into TRACC constructs and co-expressed in HEK293T cells in cis along with a UAS-luciferase reporter. We adopted previously optimized experimental parameters from SPARK (Kim et al., 2017) and SPARK2 (Kim et al., 2019), including DNA transfection amounts, incubation times, and light stimulation time (Methods). Approximately 8 hours following 10-minute stimulation with blue light, TRACC activation was measured via a luciferase assay on a plate reader (Figure 1C). Of the GPCR-ligand pairs tested, the CCR6-CCL20 pair showed the highest \pm light and \pm ligand signal ratios (2.6- and 3.2-fold, respectively). Thus, we selected this GPCR-ligand pair for subsequent experiments. Of note, we included a construct that omitted the LOV domain, a design similar to trans-Tango (Talay et al., 2017), and observed high background reporter expression and ligandindependent activation ( \pm ligand signal ratio of 1.1-fold), suggesting that the additional light-gate is crucial for minimizing background.

\section{Detecting cellular contacts in HEK293T cultures.}

Next, we tested whether TRACC could successfully detect cell-cell contacts in trans. To do this, sender and receiver HEK293T cells were separately transfected with the corresponding TRACC constructs (Figure 2A). Sender and receiver cell populations were co-plated together; 
approximately 8 hours following 10-minute blue light stimulation, TRACC activation of UASluciferase expression was measured on a plate reader (Figure 2B). We observed a robust increase in luciferase reporter expression with \pm light and \pm sender signal ratios of 5.6 -fold each. To demonstrate the versatility of a transcriptional reporter, we repeated the assay using a UASmCherry reporter in place of UAS-luciferase and performed immunostaining and confocal fluorescence imaging (Figure 2C-D). From the imaging assay, we observed robust light-dependent activation of the mCherry reporter in V5-positive (receiver-positive) cells that were in direct contact with HA-positive (sender-positive) cells. Quantitation of fluorescence intensities of cells across 50 fields of view showed that TRACC was highly specific; of 94 mCherry-expressing cells analyzed, 80.0\% were in direct contact with an HA-positive sender cell (Figure 2E). While we did observe mCherry reporter activation in V5-positive cells not touching sender cells (20\% of mCherry-expressing cells were not in direct contact with a sender cell), it is possible that these cells were previously in contact, but the sender cells were dislodged during the course of the experiment or during the washing steps in immunostaining. It is also possible that background activation may occur in cells expressing the arrestin-TEVp component at particularly high levels, which can result in GPCR activation-independent release of the transcription factor (Sanchez et al., 2021). V5 intensity distributions were consistent across high-mCherry and low-mCherry populations (Figure 2 - figure supplement 1A), suggesting that reporter activation is senderdependent and not a result of differential receiver expression levels.

To assess sensitivity, we determined that $80.2 \%$ of receiver cells in contact with sender cells showed reporter expression above background $(n=106$ cells from 50 FOVs; above background defined as having a fluorescence signal 1.5-fold or greater above a blank region). Furthermore, of 
the receiver cells in contact with an HA-positive (sender) cell, we also observed that the HA intensity within the same region of interest (ROI) was similar across both highly expressing and lowly expressing cells (Figure 2 - figure supplement 1B), suggesting the difference in activation levels is not dependent on the expression levels of the sender construct. One possible explanation for contacting cells that do not turn on TF is that they may lack one of the other two receiver components (arrestin-TEVp or UAS-mCherry) that need to be co-transfected into the same cell for TRACC to function. We also performed this experiment using lentivirus transduction instead of transient transfection and similarly observed sender- and light-dependent reporter activation (Figure 2 - figure supplement 2).

\section{Extending TRACC to neuronal systems.}

Recently developed non-viral tools for trans-synaptic tracing in neurons have expanded our ability to map synaptically connected cell populations. However, trans-Tango (Talay et al., 2017), TRACT (Huang et al., 2017), and BAcTrace (Cachero et al., 2020) have so far only been demonstrated in Drosophila and do not include mechanisms for temporal gating. To explore whether it would be feasible to adapt TRACC to neuronal systems, we cloned our constructs into AAV vectors driven by the synapsin promoter and utilized the orthogonal tTA-TRE transcription factor system (Figure 3A). We generated mixed serotype AAV1/2 viruses for infecting cultured rat neurons. First, we verified that the individual constructs expressed and localized as expected in primary rat cortical neuron culture; we were able to detect the CCR6 and arrestin receiver components and observed that these constructs trafficked to neuronal processes as expected (Figure 3 - figure supplement 1A). We also verified that the CCL20 sender construct localized 
properly to pre-synaptic terminals via colocalization with endogenous synapsin (Figure 3 - figure supplement 1B-C). Deletion of the intracellular neurexin domain disrupted its targeting specificity.

To test TRACC in neuron culture, we first co-expressed both receiver and sender constructs in the same population of neurons in cis and performed a luciferase assay. Approximately 24 hours after 10-minute blue light stimulation, we measured luciferase reporter levels on a plate reader and observed robust activation of the TRE-luciferase reporter with high \pm light and \pm ligand signal ratios of 11.4- and 7.5-fold, respectively (Figure 3B). Next, we tested our tool in a co-culture system in which HEK293T cells expressing receiver constructs were co-plated onto neurons expressing a sender construct (Figure 3C). In the luciferase assay, we detected light- and sender-dependent gene expression, with \pm light and \pm sender signal ratios of 4.2- and 3.2-fold, respectively (Figure 3D). We repeated the assay with confocal microscopy imaging and again observed robust expression of the mCherry reporter only in the presence of both light and sender (Figure 3E). Lastly, we showed trans-cellular activation of TRACC in the reverse configuration, with sender HEK293T cells co-plated onto neurons expressing receiver constructs; both luciferase and imaging assays are shown in Figure 3 - figure supplement 1D-F.

\section{Detecting interactions between neurons and glioma cells.}

High-grade gliomas are lethal brain cancers and the leading cause of brain tumor death in both children and adults (Johung and Monje, 2017). Recent studies have shown that neuronal interactions with glioma cells drive glioma progression (Pan et al., 2021; Venkatesh et al., 2019, 2017, 2015). Gliomas integrate into neural circuits, and one key mechanism driving glioma progression is signaling through functional neuron-to-glioma synapses (Venkataramani et al., 
2019; Venkatesh et al., 2019). In these connections, pre-synaptic neurons communicate electrochemically to post-synaptic glioma cells, and the consequent inward current promotes glioma cell proliferation through membrane voltage-sensitive mechanisms (Venkatesh et al., 2019). How the synaptic connectivity evolves over the course of the cancer, which neurons form synapses with glioma cells, and which subpopulations of these cellularly heterogeneous tumors (Filbin et al., 2018; Venteicher et al., 2017) engage in neuron-to-glioma synapses has yet to be determined. We hypothesized that applying TRACC to experimental model systems of glioma may open the door to future studies of neuron-to-glioma connectivity at various timepoints in the evolution of the disease course as well as isolation of synaptic subpopulations for subsequent molecular analysis.

To see whether TRACC could be adapted for detecting contacts between neurons and glioma cells, we generated transposon-integrated cell lines stably expressing receiver constructs using patientderived diffuse intrinsic pontine glioma (DIPG) cells (Figure 4A). We observed that SU-DIPG-VI cells stably expressing TRACC components exhibited low sensitivity; only a small fraction of cells showed mCherry reporter expression upon activation of TRACC with recombinant ligand and exogenous blue light (Figure 4A; Figure 4 - figure supplement 1A). To further optimize TRACC in this system, we generated 5 additional receiver cell lines containing variants of either the LOV domain or the TEV protease. We compared eLOV versus hLOV, which combines features of eLOV and iLiD (Kim et al., 2017). We also compared wild-type TEV protease with faster variants that were engineered via directed evolution, uTEV1 and uTEV2 (Sanchez and Ting, 2020). From screening the SU-DIPG-VI cell lines expressing the different combinations of LOV and TEVp, we found that eLOV in combination with uTEV2 showed the highest sensitivity (Figure 4A; Figure 4 
- figure supplement 1A). Furthermore, while the proportion of cells that became activated increased, this activation was still highly specific and required the presence of both recombinant ligand and blue light (Figure 4A). We tested this cell line in a co-culture system in which SUDIPG-VI cells stably expressing receiver constructs (with eLOV and uTEV2) were co-plated onto neurons expressing the sender construct (Figure 4B). In this assay, we observed robust activation of the mCherry reporter only in the presence of both light and sender expression in sender neurons (Figure 4C; Figure 4 - figure supplement 1B), demonstrating the potential to map neuron-glioma cell-cell contact interactions in patient-derived glioma model systems.

\section{Discussion}

We have adapted our previously published SPARK tool (Kim et al., 2017), an assay for detecting protein-protein interactions, into a tool for detecting cell-cell contacts. TRACC is a GPCR-based detector of cell-cell interactions with transcriptional readout, offering versatile outputs for detection and downstream manipulation. TRACC incorporates the light-sensitive LOV domain, such that tool activation can only occur in a user-defined window during which exogenous blue light is supplied. Compared to tools that directly label contact sites such as LIPSTIC (Pasqual et al., 2018), split-HRP (Martell et al., 2016), and mGRASP (Kim et al., 2012), TRACC provides genetic access to contacting cell populations for downstream analysis and potential manipulation. Furthermore, in comparison to other transcription factor-based tools like SynNotch (Morsut et al., 2016) and trans-Tango (Talay et al., 2017), the incorporation of light gating in TRACC substantially reduces background signal and provides temporal specificity for detecting cell-cell contacts during user-defined time windows. 
We used TRACC to detect cell-cell contacts between separately transfected HEK293T cell populations and observed specific and sensitive tool activation. We further showed that TRACC can be applied to detect cellular contacts in both neuron and glioma systems, and that the sender construct localizes properly to pre-synaptic terminals. In future studies, TRACC may be useful for synapse-specific tracing, particular in the anterograde direction (pre-synaptic to post-synaptic) for which tools are currently lacking. This will first require careful validation of TRACC component localization in vivo and testing of TRACC specificity and sensitivity in a well-characterized circuit in vivo. TRACC may also be useful for future investigations of neuron-glioma circuitry, allowing identification and subsequent analysis of connected subpopulations.

\section{Acknowledgements}

This work was supported by the NIH (RF1 MH117821 to A.Y.T., DP1NS111132 to M.M.) and

Stanford Wu Tsai Neurosciences Institute (Big Ideas initiative to A.Y.T.). K.F.C. was supported by NIH Training Grant 2T32CA009302-41 and the Blavatnik Graduate Fellowship. A.Y.T. is an investigator of the Chan Zuckerberg Biohub. 


\section{Methods}

Table 1. Table of plasmids used in this study.

\begin{tabular}{|c|c|c|c|c|c|c|c|}
\hline $\begin{array}{l}\text { Plasmid } \\
\text { name }\end{array}$ & $\begin{array}{l}\text { Plasmid } \\
\text { vector }\end{array}$ & Promoter & Features & Variants & Details & Used for & Used in \\
\hline P1-P6 & pAAV & $\mathrm{CMV}$ & $\begin{array}{c}\text { HindIII- } \\
\text { GPCR- } \\
\text { SpeI- } \\
\text { NES- } \\
\text { NheI- } \\
\text { eLOV- } \\
\text { TEVcs- } \\
\text { FLAG- } \\
\text { Gal4-V5 }\end{array}$ & $\begin{array}{c}\text { GPCRs: } \\
\text { CCR3, CCR6, } \\
\text { CCR7, } \\
\text { GHRHR, } \\
\text { GNRHR, } \\
\text { GCGR }\end{array}$ & $\begin{array}{c}\text { NES: } \\
\text { ELAEKLAGLDI } \\
\text { N; TEVcs: } \\
\text { ENLYFQM; } \\
\text { FLAG: } \\
\text { DYKDDDDK; } \\
\text { V5: } \\
\text { GKPIPNPLLGL } \\
\text { DST }\end{array}$ & $\begin{array}{l}\text { Transient } \\
\text { expression }\end{array}$ & $\begin{array}{l}\text { Figure 1, 2, } \\
\text { 3; Figure 2 } \\
\text { - figure } \\
\text { supplement } \\
1\end{array}$ \\
\hline P7 & pAAV & CMV & $\begin{array}{c}\text { HindIII- } \\
\text { GPCR- } \\
\text { SpeI- } \\
\text { NES- } \\
\text { NheI- } \\
\text { TEVcs- } \\
\text { FLAG- } \\
\text { Gal4-V5 }\end{array}$ & GPCR: GCGR & $\begin{array}{c}\text { NES: } \\
\text { ELAEKLAGLDI } \\
\text { N; TEVcs: } \\
\text { ENLYFQM; } \\
\text { FLAG: } \\
\text { DYKDDDDK; } \\
\text { V5: } \\
\text { GKPIPNPLLGL } \\
\text { DST }\end{array}$ & $\begin{array}{c}\text { Transient } \\
\text { expression }\end{array}$ & Figure 1 \\
\hline P8-P13 & pCAG & $\mathrm{CAG}$ & $\begin{array}{c}\text { KpnI- } \\
\text { Ligand-18 } \\
\text { aa linker- } \\
\text { AgeI- } \\
\text { 3xHA- } \\
\text { AgeI-pre- } \\
\text { mGRASP }\end{array}$ & $\begin{array}{c}\text { Ligands: } \\
\text { CCL13, } \\
\text { CCL20, } \\
\text { CCL19, } \\
\text { GHRH, } \\
\text { GnRH, GCG }\end{array}$ & $\begin{array}{c}18 \text { aa linker: } \\
\text { GNGNGNGNG } \\
\text { NGNGNGNGN; } \\
\text { 3xHA: } \\
\text { AAVYPYDVPD } \\
\text { YAGYPYDVPD } \\
\text { YAGSYPYDVP } \\
\text { DYAPAA }\end{array}$ & $\begin{array}{c}\text { Transient } \\
\text { expression }\end{array}$ & $\begin{array}{l}\text { Figure 1, 2; } \\
\text { Figure 2- } \\
\text { figure } \\
\text { supplement } \\
\quad 1,2\end{array}$ \\
\hline P14 & pCDNA3 & $\mathrm{CMV}$ & $\begin{array}{l}\text { BsaI-myc- } \\
\text { Arrestin- } \\
10 \text { aa } \\
\text { linker- } \\
\text { TEVp } \\
\end{array}$ & & $\begin{array}{c}10 \text { aa linker: } \\
\text { GGSGSGSGGS }\end{array}$ & $\begin{array}{l}\text { Transient } \\
\text { expression }\end{array}$ & $\begin{array}{l}\text { Figure 1, 2, } \\
3 \text {; Figure } 2 \\
\text { - figure } \\
\text { supplement } \\
1 \\
\end{array}$ \\
\hline P15-16 & pAAV & UAS & Reporter & $\begin{array}{l}\text { Reporters: } \\
\text { Luciferase, } \\
\text { mCherry }\end{array}$ & & $\begin{array}{c}\text { Transient } \\
\text { expression }\end{array}$ & $\begin{array}{c}\text { Figure 1, 2, } \\
3 \text {; Figure 2 } \\
\text { - figure } \\
\text { supplement } \\
1\end{array}$ \\
\hline P17 & AAV1 & & & & & $\begin{array}{c}\text { Producing } \\
\text { AAV1/2 } \\
\text { virus }\end{array}$ & $\begin{array}{c}\text { Figure } 3,4 ; \\
\text { Figure } 3- \\
\text { figure } \\
\text { supplement } \\
1 \\
\end{array}$ \\
\hline P18 & AAV2 & & & & & $\begin{array}{c}\text { Producing } \\
\text { AAV1/2 } \\
\text { virus }\end{array}$ & $\begin{array}{c}\text { Figure 3, 4; } \\
\text { Figure } 3- \\
\text { figure } \\
\text { supplement } \\
\quad 1 \\
\end{array}$ \\
\hline P19 & DF6 & & & & & $\begin{array}{c}\text { Producing } \\
\text { AAV1/2 } \\
\text { virus }\end{array}$ & $\begin{array}{l}\text { Figure } 3,4 ; \\
\text { Figure } 3- \\
\text { figure }\end{array}$ \\
\hline
\end{tabular}




\begin{tabular}{|c|c|c|c|c|c|c|c|}
\hline & & & & & & & $\begin{array}{c}\text { supplement } \\
1\end{array}$ \\
\hline P20 & pAAV & Synapsin & $\begin{array}{l}\text { BamHI- } \\
\text { CCL20-18 } \\
\text { aa linker- } \\
\text { AgeI- } \\
\text { 3xHA- } \\
\text { AgeI-pre- } \\
\text { mGRASP }\end{array}$ & & $\begin{array}{c}18 \text { aa linker: } \\
\text { GNGNGNGNG } \\
\text { NGNGNGNGN; } \\
\text { 3xHA: } \\
\text { AAVYPYDVPD } \\
\text { YAGYPYDVPD } \\
\text { YAGSYPYDVP } \\
\text { DYAPAA }\end{array}$ & $\begin{array}{c}\text { AAV- } \\
\text { induced } \\
\text { expression } \\
\text { in neurons }\end{array}$ & $\begin{array}{c}\text { Figure 3, 4; } \\
\text { Figure } 3- \\
\text { figure } \\
\text { supplement } \\
\quad 1\end{array}$ \\
\hline P21 & pAAV & Synapsin & $\begin{array}{c}\text { BamHI- } \\
\text { CCR6- } \\
\text { SpeI- } \\
\text { NES- } \\
\text { NheI- } \\
\text { eLOV- } \\
\text { TEVcs- } \\
\text { FLAG- } \\
\text { tTA }\end{array}$ & & $\begin{array}{c}\text { NES: } \\
\text { ELAEKLAGLDI } \\
\text { N; TEVcs: } \\
\text { ENLYFQM; } \\
\text { FLAG: } \\
\text { DYKDDDDK }\end{array}$ & $\begin{array}{c}\text { AAV- } \\
\text { induced } \\
\text { expression } \\
\text { in neurons }\end{array}$ & $\begin{array}{c}\text { Figure 3; } \\
\text { Figure 3- } \\
\text { figure } \\
\text { supplement } \\
\quad 1\end{array}$ \\
\hline P22 & pAAV & Synapsin & $\begin{array}{c}\text { Arrestin- } \\
10 \text { aa } \\
\text { linker- } \\
\text { TEVp-V5 }\end{array}$ & & $\begin{array}{c}10 \text { aa linker: } \\
\text { GGSGSGSGGS; } \\
\text { V5: } \\
\text { GKPIPNPLLGL } \\
\text { DST } \\
\end{array}$ & $\begin{array}{c}\text { AAV- } \\
\text { induced } \\
\text { expression } \\
\text { in neurons }\end{array}$ & $\begin{array}{c}\text { Figure 3; } \\
\text { Figure 3- } \\
\text { figure } \\
\text { supplement } \\
1 \\
\end{array}$ \\
\hline P23-24 & pAAV & TRE & Reporter & $\begin{array}{l}\text { Reporters: } \\
\text { Luciferase, } \\
\text { mCherry }\end{array}$ & & $\begin{array}{c}\text { AAV- } \\
\text { induced } \\
\text { expression } \\
\text { in neurons }\end{array}$ & $\begin{array}{c}\text { Figure 3; } \\
\text { Figure 3- } \\
\text { figure } \\
\text { supplement } \\
1\end{array}$ \\
\hline $\mathrm{P} 25$ & pAAV & Synapsin & GFP & & & $\begin{array}{c}\text { AAV- } \\
\text { induced } \\
\text { expression } \\
\text { in neurons }\end{array}$ & Figure 3,4 \\
\hline P26-27 & pPB & EF-1 $\alpha$ & $\begin{array}{c}\text { AgeI- } \\
\text { CCR6- } \\
\text { SpeI- } \\
\text { NES- } \\
\text { NheI- } \\
\text { LOV- } \\
\text { TEVcs- } \\
\text { FLAG- } \\
\text { Gal4 } \\
\end{array}$ & $\begin{array}{l}\text { LOV variants: } \\
\text { eLOV, hLOV }\end{array}$ & $\begin{array}{c}\text { NES: } \\
\text { ELAEKLAGLDI } \\
\text { N; TEVcs: } \\
\text { ENLYFQM; } \\
\text { FLAG: } \\
\text { DYKDDDDK }\end{array}$ & $\begin{array}{c}\text { Stable } \\
\text { expression } \\
\text { in DIPG }\end{array}$ & $\begin{array}{c}\text { Figure 4; } \\
\text { Figure 4- } \\
\text { figure } \\
\text { supplement } \\
1\end{array}$ \\
\hline P28-30 & $\mathrm{pPB}$ & $\begin{array}{l}\text { UbC; } \\
\text { UAS }\end{array}$ & $\begin{array}{l}\text { Arrestin- } \\
10 \text { aa } \\
\text { linker- } \\
\text { TEVp-V5; } \\
\text { UAS- } \\
\text { mCherry } \\
\end{array}$ & $\begin{array}{c}\text { TEVp } \\
\text { variants: WT } \\
\text { TEVp, } \\
\text { uTEV1, } \\
\text { uTEV2 }\end{array}$ & $\begin{array}{c}10 \text { aa linker: } \\
\text { GGSGSGSGGS; } \\
\text { V5: } \\
\text { GKPIPNPLLGL } \\
\text { DST }\end{array}$ & $\begin{array}{c}\text { Stable } \\
\text { expression } \\
\text { in DIPG }\end{array}$ & $\begin{array}{c}\text { Figure 4; } \\
\text { Figure } 4- \\
\text { figure } \\
\text { supplement } \\
\quad 1\end{array}$ \\
\hline P31 & pPB & & & & $\begin{array}{c}\text { Super PiggyBac } \\
\text { Transposase } \\
\text { Expression } \\
\text { Vector (System } \\
\text { Biosciences) } \\
\end{array}$ & $\begin{array}{c}\text { Stable } \\
\text { expression } \\
\text { in DIPG }\end{array}$ & $\begin{array}{c}\text { Figure 4; } \\
\text { Figure 4- } \\
\text { figure } \\
\text { supplement } \\
1 \\
\end{array}$ \\
\hline P31 & pCMV & $\mathrm{CMV}$ & dR8.91 & & & $\begin{array}{l}\text { Producing } \\
\text { lentivirus }\end{array}$ & $\begin{array}{l}\text { Figure } 2- \\
\text { figure }\end{array}$ \\
\hline
\end{tabular}




\begin{tabular}{|c|c|c|c|c|c|c|}
\hline & & & & & & $\begin{array}{c}\text { supplement } \\
2\end{array}$ \\
\hline P32 & pCMV & CMV & VSV-G & & $\begin{array}{l}\text { Producing } \\
\text { lentivirus }\end{array}$ & $\begin{array}{c}\text { Figure } 2- \\
\text { figure } \\
\text { supplement } \\
2\end{array}$ \\
\hline P33 & pLX208 & CMV & $\begin{array}{l}\text { CCR6- } \\
\text { SpeI- } \\
\text { NES- } \\
\text { NheI- } \\
\text { eLOV- } \\
\text { TEVcs- } \\
\text { FLAG- } \\
\text { Gal4 }\end{array}$ & $\begin{array}{c}\text { NES: } \\
\text { ELAEKLAGLDI } \\
\text { N; TEVcs: } \\
\text { ENLYFQM; } \\
\text { FLAG: } \\
\text { DYKDDDDK }\end{array}$ & $\begin{array}{l}\text { Lentivirus } \\
\text {-induced } \\
\text { expression } \\
\text { in } \\
\text { HEK293T }\end{array}$ & $\begin{array}{l}\text { Figure } 2- \\
\text { figure } \\
\text { supplement } \\
2\end{array}$ \\
\hline P34 & pLX208 & CMV & $\begin{array}{c}\text { Arrestin- } \\
10 \text { aa } \\
\text { linker- } \\
\text { TEVp }\end{array}$ & $\begin{array}{c}10 \text { aa linker: } \\
\text { GGSGSGSGGS }\end{array}$ & $\begin{array}{c}\text { Lentivirus } \\
\text {-induced } \\
\text { expression } \\
\text { in } \\
\text { HEK293T } \\
\end{array}$ & $\begin{array}{l}\text { Figure } 2- \\
\text { figure } \\
\text { supplement } \\
2\end{array}$ \\
\hline P35 & pLX208 & CMV & $\begin{array}{l}\text { CCL20-18 } \\
\text { aa linker- } \\
\text { AgeI- } \\
\text { 3xHA- } \\
\text { AgeI-pre- } \\
\text { mGRASP }\end{array}$ & $\begin{array}{c}18 \text { aa linker: } \\
\text { GNGNGNGNG } \\
\text { NGNGNGNGN; } \\
\text { 3xHA: } \\
\text { AAVYPYDVPD } \\
\text { YAGYPYDVPD } \\
\text { YAGSYPYDVP } \\
\text { DYAPAA }\end{array}$ & $\begin{array}{c}\text { Lentivirus } \\
\text {-induced } \\
\text { expression } \\
\text { in } \\
\text { HEK293T }\end{array}$ & $\begin{array}{l}\text { Figure } 2- \\
\text { figure } \\
\text { supplement } \\
2\end{array}$ \\
\hline P36 & pLX208 & UAS & mCherry & & $\begin{array}{c}\text { Lentivirus } \\
\text {-induced } \\
\text { expression } \\
\text { in } \\
\text { HEK293T }\end{array}$ & $\begin{array}{l}\text { Figure } 2- \\
\text { figure } \\
\text { supplement } \\
2\end{array}$ \\
\hline
\end{tabular}


Table 2. Table of antibodies used in this study.

\begin{tabular}{|c|c|c|c|c|}
\hline Antibody & Source & Vendor & Catalog Number & Dilution(s) \\
\hline Anti-V5 & Mouse & $\begin{array}{c}\text { Thermo Fisher } \\
\text { Scientific }\end{array}$ & R96025 & WB: 1:10000; IF: 1:1000 \\
\hline Anti-HA & Rabbit & $\begin{array}{c}\text { Cell Signaling } \\
\text { Technology }\end{array}$ & $\mathrm{C} 29 \mathrm{~F} 4$ & WB: 1:5000; IF: 1:1000 \\
\hline$\overline{\text { DAPI }}$ & - & $\begin{array}{l}\text { Enzo Life } \\
\text { Sciences }\end{array}$ & AP402-0010 & $\begin{array}{l}\text { IF: } 1 \mu \mathrm{g} / \mathrm{mL} \text { final } \\
\text { concentration }\end{array}$ \\
\hline $\begin{array}{c}\text { Anti-mouse- } \\
\text { AlexaFluor488 }\end{array}$ & Goat & $\begin{array}{l}\text { Thermo Fisher } \\
\text { Scientific }\end{array}$ & A11029 & IF: $1: 1000$ \\
\hline $\begin{array}{c}\text { Anti-mouse- } \\
\text { AlexaFluor568 }\end{array}$ & Goat & $\begin{array}{l}\text { Thermo Fisher } \\
\text { Scientific }\end{array}$ & A11031 & IF: $1: 1000$ \\
\hline $\begin{array}{c}\text { Anti-mouse- } \\
\text { AlexaFluor647 }\end{array}$ & Goat & $\begin{array}{c}\text { Thermo Fisher } \\
\text { Scientific }\end{array}$ & A21236 & IF: $1: 1000$ \\
\hline $\begin{array}{c}\text { Anti-rabbit- } \\
\text { AlexaFluor488 }\end{array}$ & Goat & $\begin{array}{c}\text { Thermo Fisher } \\
\text { Scientific }\end{array}$ & A11008 & IF: $1: 1000$ \\
\hline $\begin{array}{c}\text { Anti-rabbit- } \\
\text { AlexaFluor568 }\end{array}$ & Goat & $\begin{array}{c}\text { Thermo Fisher } \\
\text { Scientific }\end{array}$ & A11036 & IF: $1: 1000$ \\
\hline $\begin{array}{c}\text { Anti-rabbit- } \\
\text { AlexaFluor647 }\end{array}$ & Goat & $\begin{array}{c}\text { Thermo Fisher } \\
\text { Scientific }\end{array}$ & A21245 & IF: $1: 1000$ \\
\hline Anti-RFP & Rabbit & Rockland & $600-401-379$ & IF: $1: 1000$ \\
\hline Anti-VP16 & Rabbit & Abcam & Ab4808 & IF: $1: 1000$ \\
\hline Anti-Synapsin & Guinea Pig & $\begin{array}{l}\text { Synaptic } \\
\text { Systems }\end{array}$ & 106004 & IF: $1: 500$ \\
\hline Anti-NFH & Chicken & Aves Labs & $\mathrm{NFH}$ & IF: $1: 2000$ \\
\hline $\begin{array}{c}\text { RFP-Booster } \\
\text { AlexaFluor } 568\end{array}$ & Alpaca & Chromotek & rb2AF568-50 & IF: $1: 500$ \\
\hline
\end{tabular}




\section{Cloning}

All constructs were generated using standard cloning techniques. PCR fragments were amplified using Q5 polymerase (NEB). Vectors were digested using enzymatic restriction digest and ligated to gel purified PCR products using Gibson assembly. Ligated plasmid products were transformed into either competent XL1-Blue bacteria or competent NEB Stable bacteria (C3040H).

\section{Cell lines}

HEK293T cells were obtained from ATCC; SU-DIPG cell lines were patient derived. All cell lines have been tested mycoplasma negative.

\section{HEK293T cell culture and transfection}

HEK293T cells from ATCC were cultured as a monolayer in complete media: Dulbecco's Modified Eagle's Medium (DMEM) with $4.5 \mathrm{~g} / \mathrm{L}$ glucose and L-glutamine supplemented with 10\% (w/v) fetal bovine serum, 1\% (v/v) GlutaMAX, 50 units $/ \mathrm{mL}$ penicillin, and $50 \mu \mathrm{g} / \mathrm{mL}$ streptomycin at $37^{\circ} \mathrm{C}$ under $5 \% \mathrm{CO}_{2}$. For confocal imaging experiments, glass coverslips were coated with $50 \mu \mathrm{g} / \mathrm{mL}$ fibronectin in DPBS for at least 20 minutes at room temperature before plating; cells were grown on glass coverslips in 24 -well plates with $500 \mu \mathrm{L}$ growth medium. For luciferase assays, cells were grown in 24-well plates with $500 \mu \mathrm{L}$ growth medium, transfected, and replated into 96-well plates with $100 \mu \mathrm{L}$ growth medium (20,000 cells/well) 4 hours after transfection.

For transient expression, cells were transfected at approximately $70 \%$ confluency using $5 \mu \mathrm{L} / \mathrm{mL}$ Lipofectamine2000 and corresponding expression plasmids in serum-free media. Complete 
transfection protocols for individual experiments are described below. Note that for all HEK293T cell experiments expressing receiver constructs, it is critical to light-stimulate cultures $15-18$ hours post-transfection and to perform the assay (luciferase or fixation for imaging) 7-9 hours poststimulation to avoid background accumulation.

\section{Primary rat cortical neuron culture and AAV infection}

Cortical neurons were harvested from rat embryos euthanized at embryonic day 18 and plated in 24-well plates or 48-well plates as previously described (Loh et al., 2016; Wang et al., 2017). Plates were coated with $0.001 \%(\mathrm{w} / \mathrm{v})$ poly-L-ornithine in DPBS at room temperature overnight, washed twice with DPBS, and subsequently coated with $5 \mu \mathrm{g} / \mathrm{mL}$ of mouse laminin in DPBS at $37^{\circ} \mathrm{C}$ for at least 4 hours. Neurons were cultured in complete neuronal media: 1:1 Advanced DMEM:neurobasal, supplemented with 2\% (v/v) B27 supplement, 5\% (v/v) fetal bovine serum, 1\% GlutaMAX, 50 units/mL penicillin, $50 \mu \mathrm{g} / \mathrm{mL}$ streptomycin, $0.1 \%$ (v/v) $\beta$-mercaptoethanol, 5 $\mathrm{ng} / \mathrm{mL}$ glial derived neurotrophic factor (GDNF), and $5 \mu \mathrm{M}$ TRO19622 at $37^{\circ} \mathrm{C}$ under $5 \% \mathrm{CO}_{2}$. At DIV2, half of the media was removed from each well and replaced with complete neuronal media supplemented with $10 \mu \mathrm{M}$ 5-fluorodeoxyuridine (FUDR) to inhibit glial cell growth. Half of the media was replaced with complete neuronal media every 2 days afterwards.

\section{SU-DIPG-VI culture and transposon integration}

Diffuse intrinsic pontine glioma (DIPG) cells (SU-DIPG, an H3.3K27M+ patient-derived neurosphere culture) were cultured in tumor stem media: neurobasal (-A), supplemented with 20 ng/mL human bFGF, 20 ng/mL human EGF, 10 ng/mL human PDGF-AA, 10 ng/mL PDGF-BB, and $2 \mathrm{ng} / \mathrm{mL}$ heparin at $37^{\circ} \mathrm{C}$ under $5 \% \mathrm{CO}_{2}$. 
To generate transposon-integrated stable cell lines, naive glioma cells were plated in tumor stem media in 6-well plates. Plates were coated first with $0.01 \%$ poly-D-lysine for 20 minutes and then with $5 \mu \mathrm{g} / \mathrm{mL}$ of mouse laminin for 3 hours. Approximately 400,000 cells were plated per well, and cells were incubated overnight. Receiver constructs were introduced sequentially. Once cells were fully adhered, $1.5 \mu \mathrm{g}$ of a receiver construct was added to $8.5 \mu \mathrm{L}$ of FuGene HD (Promega), $0.8 \mu \mathrm{g}$ of Super PiggyBac Transposase Expression Vector, and $30 \mu \mathrm{L}$ of OptiMEM serum-free media per condition. Approximately 5 hours after transfection, a half-media change was performed to remove FuGene HD toxicity. Adherent glioma cells were expanded into $10 \mathrm{~cm}^{2}$ petri dishes, after which antibiotic selection was initiated $(1 \mu \mathrm{g} / \mathrm{mL}$ blasticidin or $100 \mu \mathrm{g} / \mathrm{mL} \mathrm{G} 418$ (Geneticin)). The transfection protocol was repeated to introduce the second receiver construct. Cells were maintained under double selection conditions until needed for in vitro experiments.

\section{Sample-size estimation and replication}

No statistical methods were used to determine sample size, and instead relied on guidelines from previously published works. For luminescence assays, we used at least four technical replicates. Sample sizes are listed in figure legends. All experiments were replicated at least once (biological replicates). Replicates are listed in figure legends.

\section{Luciferase assays with HEK293T}

For experiments with a luciferase reporter, HEK293T cells were cultured in 24-well plates and transfected with $70 \mathrm{ng}$ of pAAV-CMV-GPCR-eLOV-TEVcs-Gal4, 20 ng of pAAV-CMVArrestin-TEVp, and $30 \mathrm{ng}$ of pAAV-UAS-luciferase. For conditions with cis activation, $50 \mathrm{ng}$ of pCAG-CAG-Sender-pre-mGRASP was also included. For each condition, plasmid DNA was 
mixed with $2.5 \mu \mathrm{L}$ Lipofectamine 2000 in $50 \mu \mathrm{L}$ serum-free DMEM and incubated at room temperature for 20 minutes. The DNA-Lipofectamine2000 mix was then added directly to each well. Cells were then incubated for 4 hours in a $37^{\circ} \mathrm{C}$ incubator. Cells were then lifted using 100 $\mu \mathrm{L}$ Trypsin and resuspended in complete media and pelleted by centrifugation for 3 minutes at 200g. Cells were then replated into 96-well white, clear-bottom microplates at a density of 20,000 cells/well. Plates were wrapped in aluminum foil and incubated for an additional 12 hours in a $37^{\circ} \mathrm{C}$ incubator.

For light stimulation, cells were exposed to an LED light array $\left(467 \mathrm{~nm}, 60 \mathrm{~mW} / \mathrm{cm}^{2}, 1\right.$ second of light every 3 seconds) at $37^{\circ} \mathrm{C}$ for 10 minutes. After light stimulation, the plate was rewrapped in aluminum foil and incubated for an additional 8 hours in a $37^{\circ} \mathrm{C}$ incubator.

For luciferase reporter measurements, the Bright-Glo Luciferase Assay System (Promega) was used. The Bright-Glo reagent was thawed at room temperature 1 hour prior to use. Media was aspirated from each well, and each well was then washed with $100 \mu \mathrm{L}$ DPBS. Next, $50 \mu \mathrm{L}$ DPBS and $50 \mu \mathrm{L}$ Bright-Glo reagent was added to each well. Luminescence was analyzed 3 minutes later at $25^{\circ} \mathrm{C}$ on a plate reader (Tecan Infinite M1000 Pro) using a $1000 \mathrm{~ms}$ acquisition time, the Green1 filter, and linear shaking for 3 seconds.

\section{HEK293T co-culture for trans assays}

For trans assays using HEK293T cells, cells were cultured in 24-well plates as described above. Receiver cells were transfected with 70 ng of pAAV-CMV-CCR6-eLOV-TEVcs-Gal4, 20 ng of pAAV-CMV-Arrestin-TEVp, and 30 ng of pAAV-UAS-luciferase. Sender cells were transfected 
with $50 \mathrm{ng}$ of pCAG-CAG-CCL20-pre-mGRASP. For each condition, plasmid DNA was mixed with $2.5 \mu \mathrm{L}$ Lipofectamine 2000 in $50 \mu \mathrm{L}$ serum-free DMEM and incubated at room temperature for 20 minutes. The DNA-Lipofectamine2000 mix was then added directly to each well. Cells were then incubated for 4 hours in a $37^{\circ} \mathrm{C}$ incubator. Cells were then lifted using $100 \mu \mathrm{L}$ Trypsin and resuspended in complete media and pelleted by centrifugation for 3 minutes at $200 \mathrm{~g}$, and further washed with DPBS twice. Receiver and sender cells were mixed at a 1:1 ratio and cells were then replated into 96-well white, clear-bottom microplates at a density of 20,000 cells/well. Plates were wrapped in aluminum foil and incubated for an additional 12 hours in a $37^{\circ} \mathrm{C}$ incubator. The luciferase reporter assay was performed as described above.

\section{Lentivirus generation and HEK293T co-culture for trans assays via lentivirus}

To generate lentivirus, HEK293T cells were cultured in T75 flasks and transfected at approximately $70 \%$ confluency with $7500 \mathrm{ng}$ of the lentiviral vector of interest and packaging plasmids pCMV-dR8.91 (6750 ng) and pCMV-VSV-G (750 ng) with $75 \mu \mathrm{L}$ of polyethyleneimine (PEI, $1 \mathrm{mg} / \mathrm{mL}$; Polysciences). Approximately 72 hours after transfection, the cell medium was collected, centrifuged for 3 minutes at $300 \mathrm{~g}$ to remove cell debris, and filtered through a $0.45 \mu \mathrm{m}$ filter. Filtered media containing lentivirus was then centrifuged at $3000 \mathrm{~g}$ in $100 \mathrm{~K}$ Millipore Amicon Filters until concentrated approximately 4-fold, and then aliquoted into $0.5 \mathrm{~mL}$ aliquots, flash-frozen in liquid nitrogen, and stored at $-80^{\circ} \mathrm{C}$. Prior to infection, viral aliquots were thawed at $37^{\circ} \mathrm{C}$.

For lentivirus trans assays in HEK293T cells, cells were cultured in 12-well plates coated with 50 $\mu \mathrm{g} / \mathrm{mL}$ fibronectin in DPBS for at least 20 minutes at room temperature before plating. Cells were 
infected with lentivirus at approximately 30\% confluency. Receiver cells were infected with 100 $\mu \mathrm{L}$ of concentrated pLX208-CMV-CCR6-eLOV-TEVcs-Gal4, $50 \mu \mathrm{L}$ of pLX208-CMV-ArrestinTEVp, and $50 \mu \mathrm{L}$ of pLX208-UAS-mCherry. Sender cells were infected with $100 \mu \mathrm{L}$ of pLX208CMV-CCL20-pre-mGRASP. Cells were wrapped in aluminum foil to protect them from light and incubated for 48 hours in a $37^{\circ} \mathrm{C}$ incubator. After 48 hours, cells were lifted and co-plated under red light to not expose cells to white/blue light. Cells were lifted using $500 \mu \mathrm{L}$ Trypsin, resuspended in complete media, and pelleted by centrifugation for 3 minutes at $300 \mathrm{~g}$. Receiver and sender cells were resuspended in complete media and mixed at a 1:1 ratio and cells were then replated onto fibronectin-coated glass coverslips in 24 -well plates at a density of 200,000 cells/well. Plates were wrapped in aluminum foil and incubated for an additional 18 hours in a $37^{\circ} \mathrm{C}$ incubator. The mCherry reporter assay was performed as described above, with the additional use of RFP-Booster AlexaFluor 568 (Chromotek) for amplifying mCherry signal.

\section{AAV1/2 production in HEK293T}

To generate supernatant AAV, HEK293T cells were cultured in T25 flasks and transfected at approximately $70 \%$ confluency with $900 \mathrm{ng}$ of the AAV vector containing the gene of interest and AAV packaging/helper plasmids AAV1 (450 ng), AAV2 (450 ng) and DF6 (1800 ng) with $25 \mu \mathrm{L}$ polyethyleneimine (PEI) in water $(\mathrm{pH} 7.3,1 \mathrm{mg} / \mathrm{mL})$ in serum-free media. After 48 hours, the cell medium containing the AAV was harvested and filtered using a $0.45 \mu \mathrm{m}$ filter.

\section{Luciferase assays with neuron culture}

Primary rat cortical neurons were harvested and cultured in 48-well plates as described above. At DIV5, supernatant AAV1/2 generated as described above were added to each well as follows. For 
expression of receiver constructs, $50 \mu \mathrm{L}$ of AAV1/2 encoding pAAV-Syn-CCR6-eLOV-TEVcstTA, $20 \mu \mathrm{L}$ of AAV1/2 encoding pAAV-Syn-Arrestin-TEVp, and $20 \mu \mathrm{L}$ of AAV1/2 encoding pAAV-TRE-luciferase was added directly to the well. For conditions with cis activation, $50 \mu \mathrm{L}$ of AAV1/2 encoding pAAV-Syn-CCL20-pre-mGRASP was also added to the well. After the media change on DIV8, plates were wrapped in aluminum foil. At DIV10, cells were exposed to an LED light array (467 nm, $60 \mathrm{~mW} / \mathrm{cm}^{2}, 1$ second of light every 3 seconds) at $37^{\circ} \mathrm{C}$ for 10 minutes. After light stimulation, the plate was rewrapped in aluminum foil and incubated for an additional 24 hours in a $37^{\circ} \mathrm{C}$ incubator.

For luciferase reporter measurements, the Bright-Glo Luciferase Assay System (Promega) was used. The Bright-Glo reagent was thawed at room temperature 1 hour prior to use. Media was aspirated from each well, and each well was then washed with $200 \mu \mathrm{L}$ DPBS. Next, $50 \mu \mathrm{L}$ DPBS and $50 \mu \mathrm{L}$ Bright-Glo reagent was added to each well, and the resulting lysates were transferred to 96 -well white, clear-bottom microplates. Luminescence was analyzed at $25^{\circ} \mathrm{C}$ on a plate reader (Tecan Infinite M1000 Pro) using a 1000 ms acquisition time, the Green-1 filter, and linear shaking for 3 seconds.

\section{Neuron and HEK293T co-culture}

Primary rat cortical neurons and HEK293T cells were cultured as described above. For co-culture assays with sender neurons and receiver HEK293T cells, $50 \mu \mathrm{L}$ of AAV1/2 encoding pAAV-SynCCL20-pre-mGRASP was added to neurons at DIV5. At DIV9, HEK293T cells were separately transfected with $70 \mathrm{ng}$ of pAAV-CMV-CCR6-eLOV-TEVes-Gal4, $20 \mathrm{ng}$ of pAAV-CMVArrestin-TEVp, and 30 ng of pAAV-UAS-luciferase, as described above. After 4 hours, HEK293T 
cells were then lifted using $100 \mu \mathrm{L}$ Trypsin and resuspended in complete media and pelleted by centrifugation for 3 minutes at 200g, and further washed with DPBS twice. HEK293T cells were then resuspended in complete neuronal media and added directly to the neuron culture at a density of 5,000 cells/well for a 48 -well plate or 10,000 cells/well for a 24 -well plate; plates were then wrapped in aluminum foil. At DIV10, cells were exposed to an LED light array (467 nm, 60 $\mathrm{mW} / \mathrm{cm}^{2}, 1$ second of light every 3 seconds) at $37^{\circ} \mathrm{C}$ for 10 minutes. After light stimulation, the plate was rewrapped in aluminum foil and incubated for an additional 8 hours in a $37^{\circ} \mathrm{C}$ incubator. The luciferase reporter assay was performed as described above.

For co-culture assays with receiver neurons and sender HEK293T cells, $50 \mu \mathrm{L}$ of AAV1/2 encoding pAAV-Syn-CCR6-eLOV-TEVcs-tTA, $20 \mu \mathrm{L}$ of AAV1/2 encoding pAAV-SynArrestin-TEVp, and $20 \mu \mathrm{L}$ of AAV1/2 encoding pAAV-TRE-luciferase was added to neurons at DIV5. At DIV9, HEK293T cells were separately transfected with 50 ng of pCAG-CAG-CCL20pre-mGRASP, as described above. After 4 hours, HEK293T cells were then lifted using $100 \mu \mathrm{L}$ Trypsin and resuspended in complete media and pelleted by centrifugation for 3 minutes at $200 \mathrm{~g}$, and further washed with DPBS twice. HEK293T cells were then resuspended in complete neuronal media and added directly to the neuron culture at a density of 5,000 cells/well for a 48-well plate or 10,000 cells/well for a 24-well plate; plates were then wrapped in aluminum foil. At DIV10, cells were exposed to an LED light array $\left(467 \mathrm{~nm}, 60 \mathrm{~mW} / \mathrm{cm}^{2}, 1\right.$ second of light every 3 seconds) at $37^{\circ} \mathrm{C}$ for 10 minutes. After light stimulation, the plate was rewrapped in aluminum foil and incubated for an additional 24 hours in a $37^{\circ} \mathrm{C}$ incubator. The luciferase reporter assay was performed as described above. 


\section{Cell culture fixation, staining, and confocal imaging}

For immunofluorescence experiments, cells were cultured, transfected, infected, and/or co-plated as described above. pAAV-UAS-mCherry and pAAV-TRE-mCherry were used in place of pAAVUAS-luciferase and pAAV-TRE-luciferase. After incubation for the indicated times poststimulation, cell cultures or co-cultures were fixed with $4 \%(\mathrm{v} / \mathrm{v})$ paraformaldehyde diluted in serum-free media and 20\% (v/v) 5x PHEM buffer (300 mM PIPES, $125 \mathrm{mM}$ HEPES, $50 \mathrm{mM}$ EGTA, $10 \mathrm{mM} \mathrm{MgCl}_{2}, 0.6 \mathrm{M}$ sucrose, $\mathrm{pH}$ 7.3) for 10 minutes. The solution was removed and cells were then permeabilized with cold methanol at $4^{\circ} \mathrm{C}$ for 10 minutes. Cells were then washed three times with PBS and blocked in 1\% BSA (w/v) in PBS for 30 minutes at room temperature. Cells were incubated with primary antibody in $1 \%$ BSA (w/v) in PBS for 3 hours at room temperature. After washing three times with PBS, cells were incubated with DAPI, secondary antibodies, and neutravidin-Alex Fluor 647 in 1\% BSA (w/v) in PBS for 1 hour at room temperature. Cells were then washed with PBS three times, mounted onto glass slides, and imaged by confocal fluorescence microscopy. Confocal imaging was performed with a Zeiss AxioObserver inverted microscope with a 20x air objective, and 40x and 63x oil-immersion objectives. The following combinations of laser excitation and emission filters were used for various fluorophores: DAPI (405 nm laser excitation, 445/40 nm emission), AlexaFluor 488 (491 nm laser excitation, 528/38 nm emission), AlexaFluor 568 (561 nm laser excitation, 617/73 nm emission), and AlexaFluor 647 (647 nm laser excitation, 680/30 nm emission). All images were collected with SlideBook (Intelligent Imaging Innovations) and processed with ImageJ.

\section{Neuron and DIPG co-culture}


Primary rat cortical neurons and SU-DIPG-VI cells were cultured as described above. For coculture assays with sender neurons and receiver SU-DIPG-VI cells, $50 \mu \mathrm{L}$ of AAV1/2 encoding pAAV-Syn-CCL20-pre-mGRASP was added to neurons at DIV5. For subsequent media changes after neuron infection with AAV, complete neuronal media without serum was used instead. At DIV9, stable DIPG cells expressing receiver constructs were dissociated using TrypLE and then pelleted by centrifugation for 3 minutes at 200g, and further washed with DPBS twice. DIPG cells were then resuspended in complete neuronal media without serum and added directly to the neuron culture at a density of 10,000 cells/well for a 24-well plate; plates were then wrapped in aluminum foil. At DIV11, cells were exposed to an LED light array $\left(467 \mathrm{~nm}, 60 \mathrm{~mW} / \mathrm{cm}^{2}, 1\right.$ second of light every 3 seconds) at $37^{\circ} \mathrm{C}$ for 10 minutes. After light stimulation, the plate was rewrapped in aluminum foil and incubated for an additional 24 hours in a $37^{\circ} \mathrm{C}$ incubator. Cells were then fixed and immunostained as described above.

\section{Specificity and sensitivity analysis for HEK293T trans assay}

For specificity analysis of imaging data in Figure 2C-E, a region of interest (ROI) was generated for each V5-positive cell (receiver). The average pixel intensities in each channel for each manually drawn ROI were measured. Pixel intensities were corrected for background by subtracting the average pixel intensities of 50 V5-, mCherry-, and HA-negative cells for each channel. Measurements for each ROI were separated into either V5-positive cells in contact $(\mathrm{n}=$ 106 cells) with an HA-positive (sender) cell or not in contact $(\mathrm{n}=108$ cells), and the mCherry/V5 signal ratios were plotted (Figure 2E). 
For sensitivity analysis of imaging data in Figure 2C-E, the mCherry signal in V5-positive (receiver) cells in contact with an HA-positive (sender) cell were measured as described above. Cells were considered mCherry-positive if the signal was greater than 1.5-fold over background, as determined from V5-negative cells. From this analysis, $80.2 \%$ of V5-positive cells in contact with an HA-positive cell showed TRACC activation and mCherry expression $(n=106$ cells from 50 FOVs).

\section{Colocalization analysis of sender construct}

Sender construct colocalization with endogenous synapsin expression in neurons (Figure 3 - figure supplement 1B-C) was quantified using the Coloc2 test for image colocalization in Fiji (Schindelin et al., 2012), which measures the correlation of pixel intensity at each location to compare HA and synapsin intensity levels.

\section{Competing Financial Interests}

The authors declare no competing financial interest. 


\section{References}

Armingol E, Officer A, Harismendy O, Lewis NE. 2021. Deciphering cell-cell interactions and communication from gene expression. Nat Rev Genet. doi:10.1038/s41576-020-00292-x

Cachero S, Gkantia M, Bates AS, Frechter S, Blackie L, McCarthy A, Sutcliffe B, Strano A, Aso Y, Jefferis GSXE. 2020. BAcTrace, a tool for retrograde tracing of neuronal circuits in Drosophila. Nat Methods 17:1254-1261. doi:10.1038/s41592-020-00989-1

Cho KF, Branon TC, Rajeev S, Svinkina T, Udeshi ND, Thoudam T, Kwak C, Rhee HW, Lee IK, Carr SA, Ting AY. 2020. Split-TurboID enables contact-dependent proximity labeling in cells. Proc Natl Acad Sci U S A 117:12143-12154. doi:10.1073/pnas.1919528117

Dustin ML. 2014. The immunological synapse. Cancer Immunol Res. doi:10.1158/23266066.CIR-14-0161

Filbin MG, Tirosh I, Hovestadt V, Shaw ML, Escalante LE, Mathewson ND, Neftel C, Frank N, Pelton K, Hebert CM, Haberler C, Yizhak K, Gojo J, Egervari K, Mount C, Van Galen P, Bonal DM, Nguyen Q De, Beck A, Sinai C, Czech T, Dorfer C, Goumnerova L, Lavarino C, Carcaboso AM, Mora J, Mylvaganam R, Luo CC, Peyrl A, Popović M, Azizi A, Batchelor TT, Frosch MP, Martinez-Lage M, Kieran MW, Bandopadhayay P, Beroukhim R, Fritsch G, Getz G, Rozenblatt-Rosen O, Wucherpfennig KW, Louis DN, Monje M, Slavc I, Ligon KL, Golub TR, Regev A, Bernstein BE, Suvà ML. 2018. Developmental and oncogenic programs in H3K27M gliomas dissected by single-cell RNA-seq. Science (80- ) 360:331-335. doi:10.1126/science.aao4750

Huang TH, Niesman P, Arasu D, Lee D, De La Cru AL, Callejas A, Hong EJ, Lois C. 2017. Tracing neuronal circuits in transgenic animals by transneuronal control of transcription (Tract). Elife 6. doi:10.7554/eLife.32027 
Johung T, Monje M. 2017. Neuronal activity in the glioma microenvironment. Curr Opin Neurobiol. doi:10.1016/j.conb.2017.10.009

Kim CK, Cho KF, Kim MW, Ting AY. 2019. Luciferase-lov bret enables versatile and specific transcriptional readout of cellular protein-protein interactions. Elife $\mathbf{8}$. doi:10.7554/eLife.43826

Kim J, Zhao T, Petralia RS, Yu Y, Peng H, Myers E, Magee JC. 2012. MGRASP enables mapping mammalian synaptic connectivity with light microscopy. Nat Methods 9:96-102. doi:10.1038/nmeth.1784

Kim MW, Wang W, Sanchez MI, Coukos R, von Zastrow M, Ting AY. 2017. Time-gated detection of protein-protein interactions with transcriptional readout. Elife 6. doi:10.7554/eLife.30233

Liu DS, Loh KH, Lam SS, White KA, Ting AY. 2013. Imaging Trans-Cellular NeurexinNeuroligin Interactions by Enzymatic Probe Ligation. PLoS One 8. doi:10.1371/journal.pone.0052823

Loh KH, Stawski PS, Draycott AS, Udeshi ND, Lehrman EK, Wilton DK, Svinkina T, Deerinck TJ, Ellisman MH, Stevens B, Carr SA, Ting AY. 2016. Proteomic Analysis of Unbounded Cellular Compartments: Synaptic Clefts. Cell 166:1295-1307.e21. doi:10.1016/j.cell.2016.07.041

Lonsdale J, Thomas J, Salvatore M, Phillips R, Lo E, Shad S, Hasz R, Walters G, Garcia F, Young N, Foster B, Moser M, Karasik E, Gillard B, Ramsey K, Sullivan S, Bridge J, Magazine H, Syron J, Fleming J, Siminoff L, Traino H, Mosavel M, Barker L, Jewell S, Rohrer D, Maxim D, Filkins D, Harbach P, Cortadillo E, Berghuis B, Turner L, Hudson E, Feenstra K, Sobin L, Robb J, Branton P, Korzeniewski G, Shive C, Tabor D, Qi L, Groch 
K, Nampally S, Buia S, Zimmerman A, Smith A, Burges R, Robinson K, Valentino K, Bradbury D, Cosentino M, Diaz-Mayoral N, Kennedy M, Engel T, Williams P, Erickson K, Ardlie K, Winckler W, Getz G, DeLuca D, Daniel MacArthur, Kellis M, Thomson A, Young T, Gelfand E, Donovan M, Meng Y, Grant G, Mash D, Marcus Y, Basile M, Liu J, Zhu J, Tu Z, Cox NJ, Nicolae DL, Gamazon ER, Im HK, Konkashbaev A, Pritchard J, Stevens M, Flutre T, Wen X, Dermitzakis ET, Lappalainen T, Guigo R, Monlong J, Sammeth M, Koller D, Battle A, Mostafavi S, McCarthy M, Rivas M, Maller J, Rusyn I, Nobel A, Wright F, Shabalin A, Feolo M, Sharopova N, Sturcke A, Paschal J, Anderson JM, Wilder EL, Derr LK, Green ED, Struewing JP, Temple G, Volpi S, Boyer JT, Thomson EJ, Guyer MS, Ng C, Abdallah A, Colantuoni D, Insel TR, Koester SE, A Roger Little, Bender PK, Lehner T, Yao Y, Compton CC, Vaught JB, Sawyer S, Lockhart NC, Demchok J, Moore HF. 2013. The Genotype-Tissue Expression (GTEx) project. Nat Genet. doi:10.1038/ng.2653

Martell JD, Yamagata M, Deerinck TJ, Phan S, Kwa CG, Ellisman MH, Sanes JR, Ting AY. 2016. A split horseradish peroxidase for the detection of intercellular protein-protein interactions and sensitive visualization of synapses. Nat Biotechnol 34:774-780. doi: $10.1038 /$ nbt.3563

Morsut L, Roybal KT, Xiong X, Gordley RM, Coyle SM, Thomson M, Lim WA. 2016. Engineering Customized Cell Sensing and Response Behaviors Using Synthetic Notch Receptors. Cell 164:780-791. doi:10.1016/j.cell.2016.01.012

Pan Y, Hysinger JD, Barron T, Schindler NF, Cobb O, Guo X, Yalçın B, Anastasaki C, Mulinyawe SB, Ponnuswami A, Scheaffer S, Ma Y, Chang K, Xia X, Toonen JA, Lennon JJ, Gibson EM, Huguenard JR, Liau LM, Goldberg JL, Monje M, Gutmann DH. 2021. NF1 
mutation drives neuronal activity-dependent initiation of optic glioma. Nature 1-6. doi:10.1038/s41586-021-03580-6

Pasqual G, Chudnovskiy A, Tas JMJ, Agudelo M, Schweitzer LD, Cui A, Hacohen N, Victora GD. 2018. Monitoring T cell-dendritic cell interactions in vivo by intercellular enzymatic labelling. Nature 553:496-500. doi:10.1038/nature25442

Sanchez MI, Nguyen QA, Wang W, Soltesz I, Ting AY. 2021. Transcriptional readout of neuronal activity via an engineered Ca2+-activated protease. Proc Natl Acad Sci U S A 117:33186-33196. doi:10.1073/PNAS.2006521117

Sanchez MI, Ting AY. 2020. Directed evolution improves the catalytic efficiency of TEV protease. Nat Methods 17:167-174. doi:10.1038/s41592-019-0665-7

Schindelin J, Arganda-Carreras I, Frise E, Kaynig V, Longair M, Pietzsch T, Preibisch S, Rueden C, Saalfeld S, Schmid B, Tinevez JY, White DJ, Hartenstein V, Eliceiri K, Tomancak P, Cardona A. 2012. Fiji: An open-source platform for biological-image analysis. Nat Methods. doi:10.1038/nmeth.2019

Takano T, Wallace JT, Baldwin KT, Purkey AM, Uezu A, Courtland JL, Soderblom EJ, Shimogori T, Maness PF, Eroglu C, Soderling SH. 2020. Chemico-genetic discovery of astrocytic control of inhibition in vivo. Nature 588:296-302. doi:10.1038/s41586-0202926-0

Talay M, Richman EB, Snell NJ, Hartmann GG, Fisher JD, Sorkaç A, Santoyo JF, Chou-Freed C, Nair N, Johnson M, Szymanski JR, Barnea G. 2017. Transsynaptic Mapping of SecondOrder Taste Neurons in Flies by trans-Tango. Neuron 96:783-795.e4. doi:10.1016/j.neuron.2017.10.011

Tang R, Murray CW, Linde IL, Kramer NJ, Lyu Z, Tsai MK, Chen LC, Cai H, Gitler AD, 
Engleman E, Lee W, Winslow MM. 2020. A versatile system to record cell-cell interactions. Elife 9:1. doi:10.7554/eLife.61080

Tsetsenis T, Boucard AA, Arac D, Brunger AT, Südhof TC. 2014. Direct visualization of transsynaptic neurexin-neuroligin interactions during synapse formation. $J$ Neurosci 34:1508315096. doi:10.1523/JNEUROSCI.0348-14.2014

Venkataramani V, Tanev DI, Strahle C, Studier-Fischer A, Fankhauser L, Kessler T, Körber C, Kardorff M, Ratliff M, Xie R, Horstmann H, Messer M, Paik SP, Knabbe J, Sahm F, Kurz FT, Acikgöz AA, Herrmannsdörfer F, Agarwal A, Bergles DE, Chalmers A, Miletic H, Turcan S, Mawrin C, Hänggi D, Liu HK, Wick W, Winkler F, Kuner T. 2019.

Glutamatergic synaptic input to glioma cells drives brain tumour progression. Nature 573:532-538. doi:10.1038/s41586-019-1564-X

Venkatesh HS, Johung TB, Caretti V, Noll A, Tang Y, Nagaraja S, Gibson EM, Mount CW, Polepalli J, Mitra SS, Woo PJ, Malenka RC, Vogel H, Bredel M, Mallick P, Monje M. 2015. Neuronal activity promotes glioma growth through neuroligin-3 secretion. Cell 161:803-816. doi:10.1016/j.cell.2015.04.012

Venkatesh HS, Morishita W, Geraghty AC, Silverbush D, Gillespie SM, Arzt M, Tam LT, Espenel C, Ponnuswami A, Ni L, Woo PJ, Taylor KR, Agarwal A, Regev A, Brang D, Vogel H, Hervey-Jumper S, Bergles DE, Suvà ML, Malenka RC, Monje M. 2019. Electrical and synaptic integration of glioma into neural circuits. Nature 573:539-545. doi:10.1038/s41586-019-1563-y

Venkatesh HS, Tam LT, Woo PJ, Lennon J, Nagaraja S, Gillespie SM, Ni J, Duveau DY, Morris PJ, Zhao JJ, Thomas CJ, Monje M. 2017. Targeting neuronal activity-regulated neuroligin-3 dependency in high-grade glioma. Nature 549:533-537. doi:10.1038/nature24014 
Venteicher AS, Tirosh I, Hebert C, Yizhak K, Neftel C, Filbin MG, Hovestadt V, Escalante LE, Shaw ML, Rodman C, Gillespie SM, Dionne D, Luo CC, Ravichandran H, Mylvaganam R, Mount C, Onozato ML, Nahed B V., Wakimoto H, Curry WT, Iafrate AJ, Rivera MN, Frosch MP, Golub TR, Brastianos PK, Getz G, Patel AP, Monje M, Cahill DP, RozenblattRosen O, Louis DN, Bernstein BE, Regev A, Suvà ML. 2017. Decoupling genetics, lineages, and microenvironment in IDH-mutant gliomas by single-cell RNA-seq. Science (80- ) 355. doi:10.1126/science.aai8478

Wang W, Wildes CP, Pattarabanjird T, Sanchez MI, Glober GF, Matthews GA, Tye KM, Ting AY. 2017. A light- A nd calcium-gated transcription factor for imaging and manipulating activated neurons. Nat Biotechnol 35:864-871. doi:10.1038/nbt.3909

Zhang Y, Liu F. 2019. Multidimensional Single-Cell Analyses in Organ Development and Maintenance. Trends Cell Biol. doi:10.1016/j.tcb.2019.02.006 


\section{Figure 1}
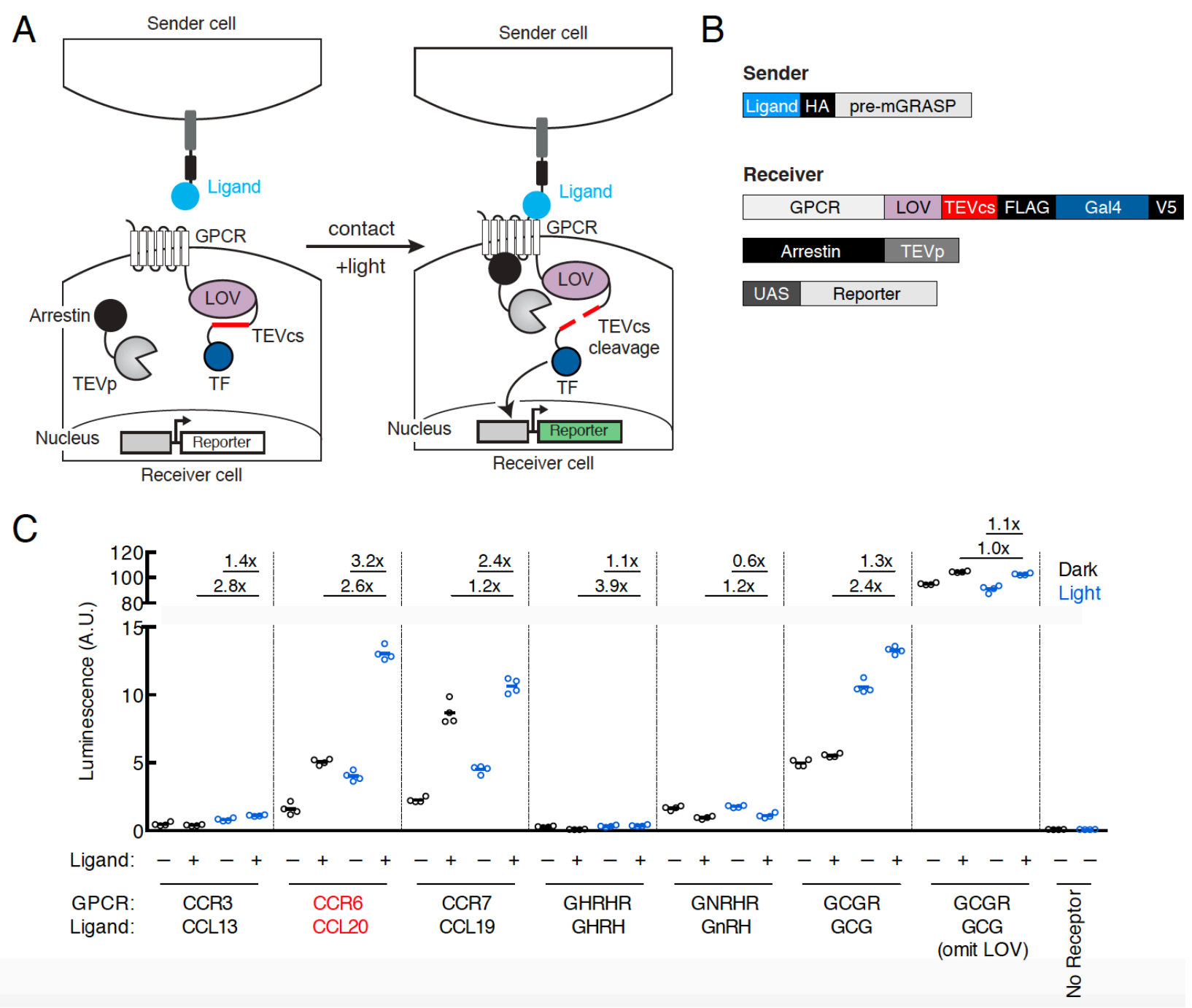

Figure 1. Design of TRACC. (A) Schematic of TRACC. A ligand is presented on sender cells; a GPCR specifically activated by the selected ligand is expressed in receiver cells. The GPCR is fused to the LOV domain, TEV protease cleavage site (TEVcs), and transcription factor (TF). Upon both cell-cell contact and exposure to blue light, the GPCR is activated and recruits arrestin fused to TEV protease (TEVp); blue light uncages the LOV domain, allowing cleavage of the TEVcs and subsequent release of the TF, which translocates to the nucleus and drives expression of a reporter of interest. (B) Constructs used in TRACC. The sender construct is comprised of a peptide ligand fused to pre-mGRASP (Kim et al., 2012) and the HA epitope tag. Receiver 
constructs include the corresponding GPCR fused to the LOV domain, TEVcs, and TF (Ga14), arrestin fused to TEVp, and a reporter construct. (C) Luciferase assay to screen a panel of GPCRligand pairs in cis. HEK293T cells were transfected with both sender and receiver constructs corresponding to each GPCR-ligand pair indicated, using the reporter UAS-luciferase. Approximately 8 hours after $10 \mathrm{~min}$. blue light exposure, the UAS-luciferase luminescence was recorded using a plate reader $(\mathrm{n}=4$ replicates per condition). The CCR6-CCL20 pair (red) showed the highest \pm light and \pm ligand signal ratios of 2.6 -fold and 3.2 -fold, respectively. A receiver construct using the glucagon receptor (GCGR), but omitting the LOV domain, analogous to that of previously published trans-Tango (Talay et al., 2017), was included as a control. 
bioRxiv preprint doi: https://doi.org/10.1101/2022.02.22.481562; this version posted February 23, 2022. The copyright holder for this preprint (which was not certified by peer review) is the author/funder, who has granted bioRxiv a license to display the preprint in perpetuity. It is made available under aCC-BY-NC-ND 4.0 International license.

\section{Figure 2}

A

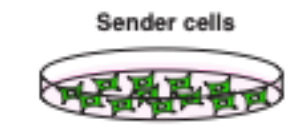

CCL2O-HA-pre-mGRASP
Receiver cells

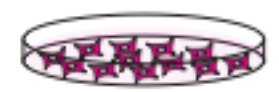

CCR6-eLOV-TEVcs-Gal4-V5

+Arrestin-TEVp

+UAS-Reporter

C
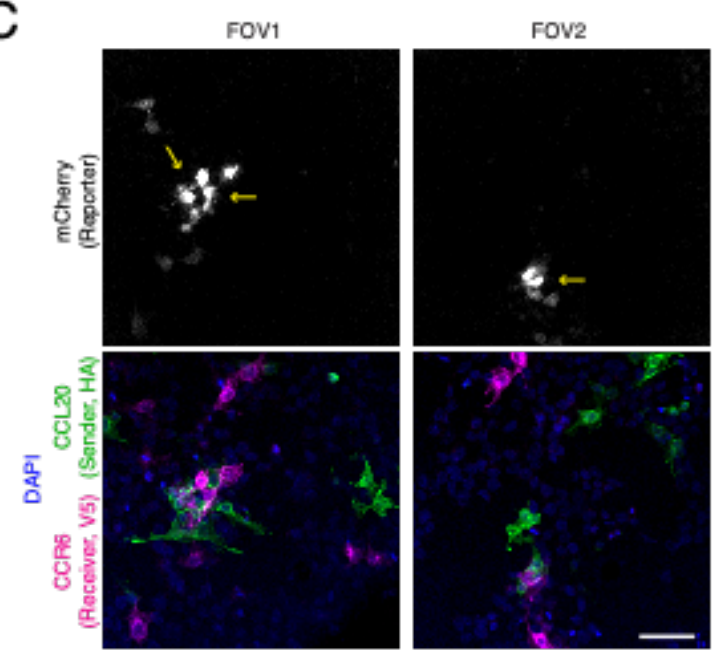

B

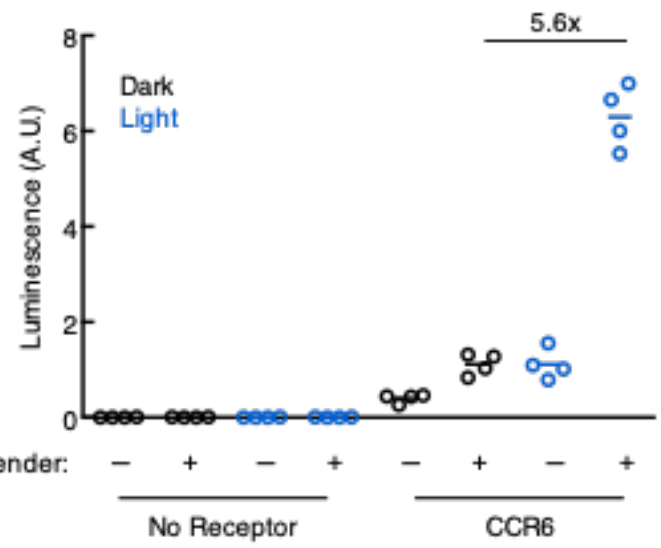

E

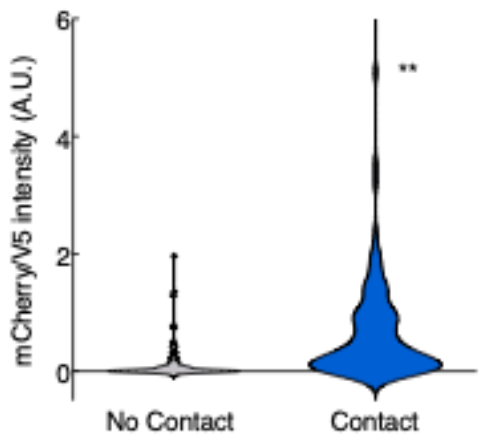

D

兹 CCL20 CCAs mCherry DAPI (Sender, HA) (Rocoiver, V5) (Reporter) Merge

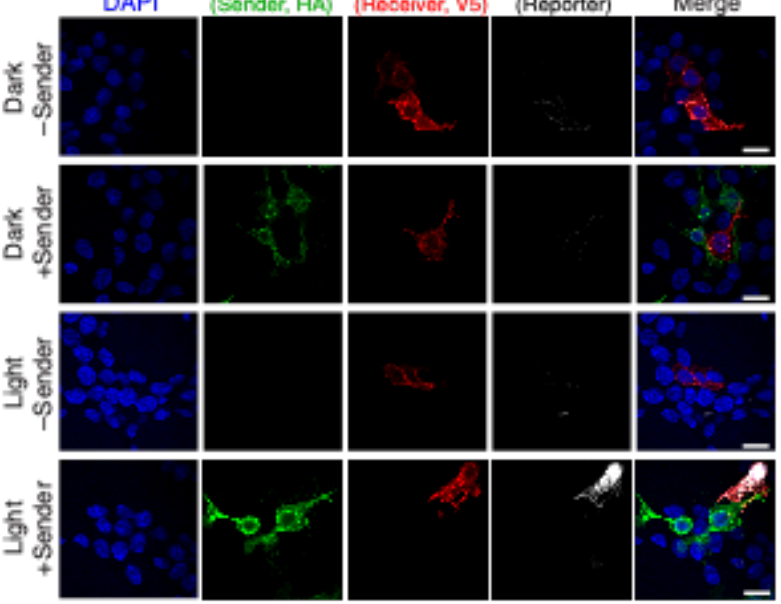

No Contact Contact 
Figure 2. Using TRACC to detect cell-cell contacts in HEK293T culture. (A) Experimental design for co-plating sender and receiver cells. (B) Luciferase assay using the CCR6-CCL20 GPCR-ligand pair in trans. HEK293T cells transfected with the CCL20 sender construct were coplated with HEK293T cells transfected with receiver constructs and UAS-luciferase. Approximately 8 hours after $10 \mathrm{~min}$. blue light exposure, the UAS-luciferase luminescence was recorded ( $\mathrm{n}=4$ replicates per condition). (C) Confocal fluorescence imaging of sender cells coplated with receiver cells, using UAS-mCherry reporter. Approximately 8 hours after $10 \mathrm{~min}$. blue light exposure, cells were fixed and immunostained. mCherry activation occurs in receiver cells (V5-positive) that contact sender cells (HA-positive). Yellow arrowheads denote examples in which receiver cells are in contact with sender cells. Scale bar, $60 \mu \mathrm{m}$. (D) Confocal fluorescence imaging of sender cells co-plated with receiver cells, using UAS-mCherry at higher magnification. Cells were treated as in (C). Scale bars, $20 \mu \mathrm{m}$. (E) Quantification of mCherry/V5 intensity ratios for all V5 positive cells in the +light condition. The mCherry/V5 ratio was significantly higher in V5-positive cells that were in contact with HA-positive sender cells. (No contact, $\mathrm{n}=108$ cells; contact, $\mathrm{n}=106$ cells; two-tailed t-test, $* * \mathrm{p}<0.005)$. 


\section{Figure 2 - figure supplement 1}
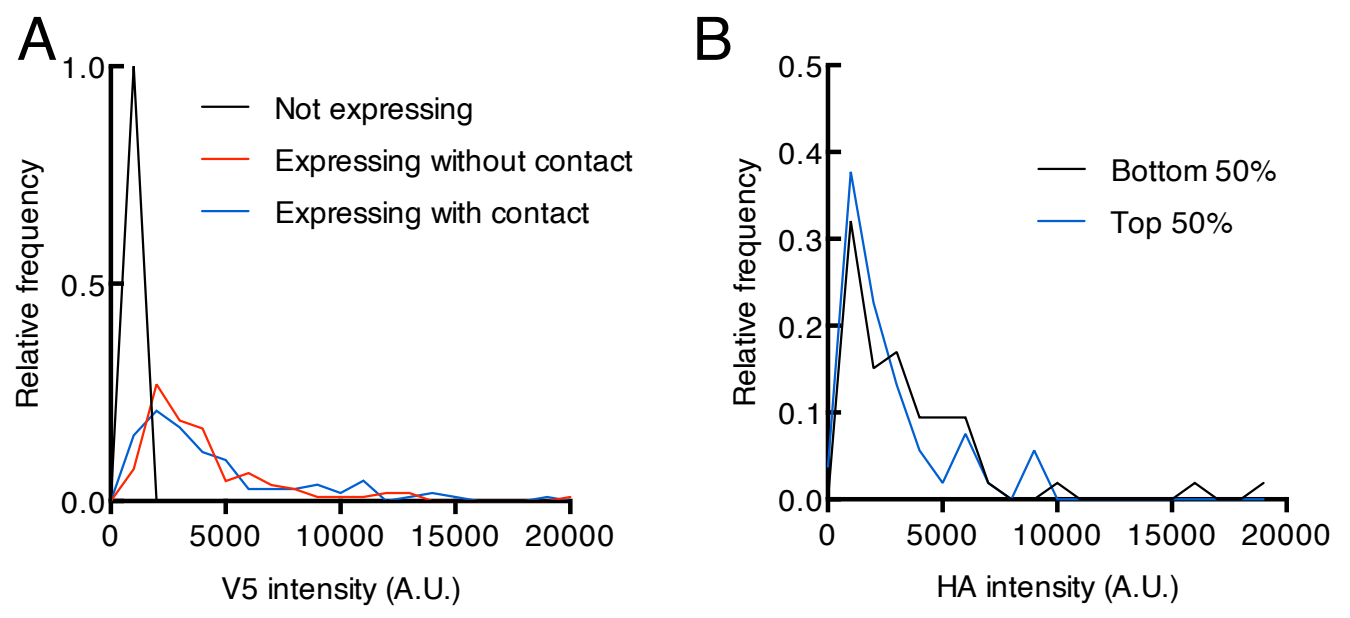

Figure 2 - figure supplement 1. Additional quantification of HEK293T imaging in trans. $(A)$

Distribution of V5 intensity in V5-positive cells in Figure 2E. The distributions of sendercontacting cells and non-contacting cells are similar, suggesting that mCherry activation is senderdependent and not a result of differential V5 expression (Not expressing, $\mathrm{n}=50$ cells, Expressing without contact, $\mathrm{n}=108$ cells, Expressing with contact, $\mathrm{n}=106$ cells). (B) Distribution of HA (sender) intensity within the same ROI (region of interest) for each V5-positive cell in contact with a sender cell. Cells were ranked based on their mCherry/V5 intensity ratios and split into groups corresponding to the top and bottom 50 percentiles. Distributions of HA intensity are similar between the two groups, suggesting factors other than differential HA (sender) expression may explain why $\sim 19.8 \%$ of contacting cells have low mCherry (reporter) expression. 


\section{Figure 2 - figure supplement 2}

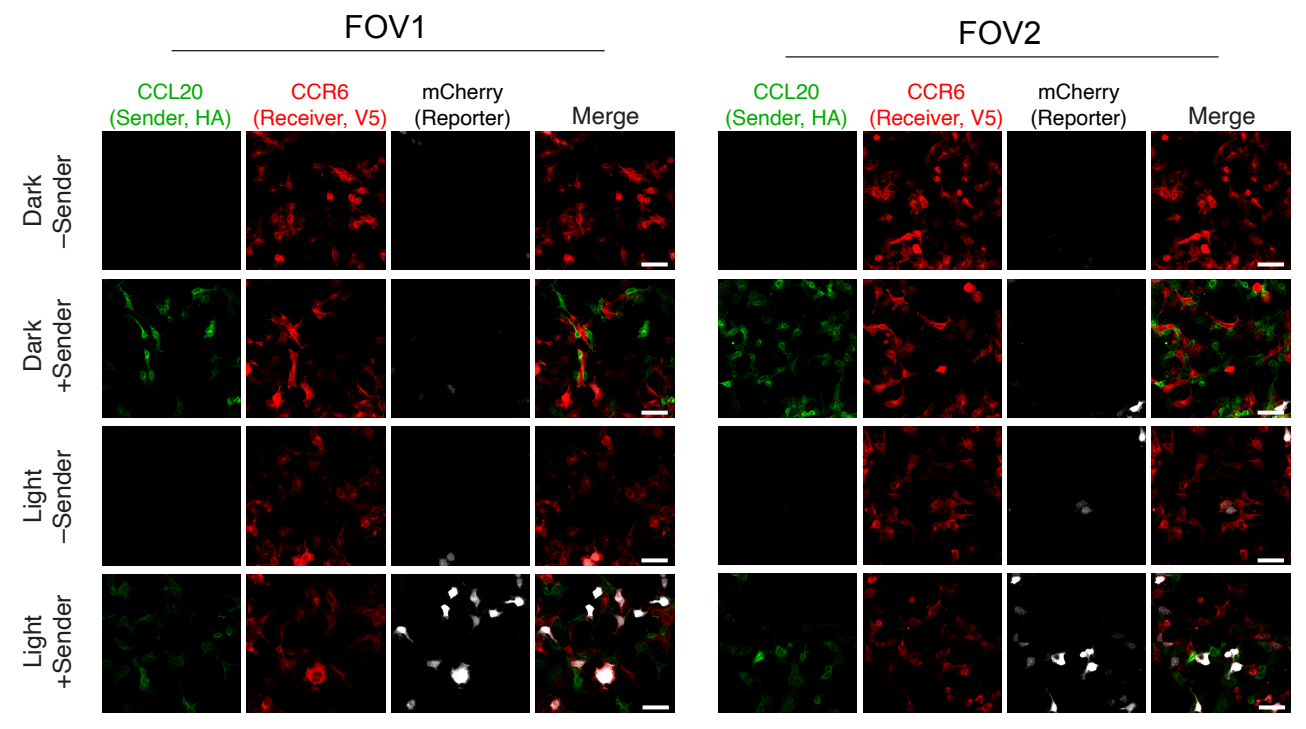

Figure 2 - figure supplement 2. Evaluation of TRACC in HEK293T cells using lentiviral

transduction. Confocal fluorescence imaging of sender cells co-plated with receiver cells using UAS-mCherry. TRACC components were introduced by lentivirus transduction. Approximately 8 hours after 10-minute blue light exposure, cells were fixed and immunostained. Scale bars, 30 $\mu \mathrm{m} . \mathrm{FOV}$, field of view. 
bioRxiv preprint doi: https://doi.org/10.1101/2022.02.22.481562; this version posted February 23, 2022. The copyright holder for this preprint (which was not certified by peer review) is the author/funder, who has granted bioRxiv a license to display the preprint in perpetuity. It is made available under aCC-BY-NC-ND 4.0 International license.

\section{Figure 3}

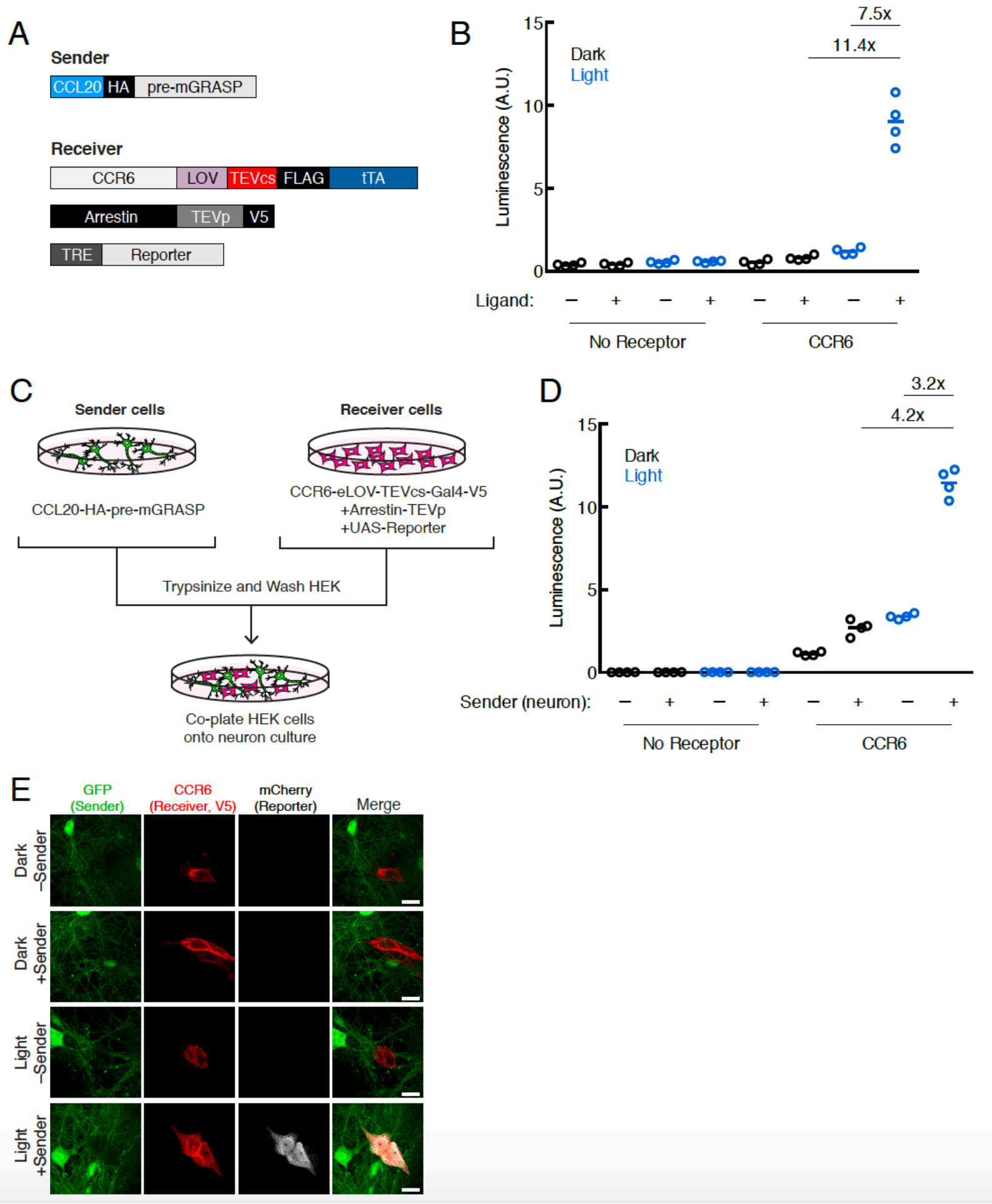




\section{Figure 3. Using TRACC to detect contacts in neuron culture and HEK293T-neuron co-} culture. (A) Constructs used in TRACC in neuron culture. CCR6 is the GPCR and CCL20 is its activating peptide ligand. For expression in neurons, the TF is changed from Gal4 to tTA and the reporter gene is driven by TRE rather than a UAS promoter. (B) Luciferase assay using TRACC constructs expressed in cis in neuron culture. Primary rat cortical neurons were infected with AAV1/2 viruses encoding both sender and receiver constructs, including the reporter TREluciferase, on DIV5 and light-stimulated on DIV10. Approximately 24 hours after 10 min. blue light exposure, the TRE-luciferase luminescence was recorded using a plate reader $(n=4$ replicates per condition). (C) Experimental design for co-plating sender neurons and receiver HEK293T cells. (D) Luciferase assay using sender neurons co-cultured with receiver HEK293T cells. Primary rat cortical neurons were infected with AAV1/2 viruses encoding the sender construct on DIV5. HEK293T cells expressing receiver constructs and UAS-luciferase were co-plated onto sender neurons on DIV9, and the resulting co-culture was light-stimulated on DIV10. Approximately 8 hours after 10 min. blue light exposure, the UAS-luciferase luminescence was recorded ( $\mathrm{n}=4$ replicates per condition). (E) Confocal fluorescence imaging of receiver HEK293T cells co-cultured with sender neurons, using UAS-mCherry. GFP driven by the synapsin promoter was included as an infection marker to visualize transduced neurons. Cells were treated as in (D). Scale bars, $20 \mu \mathrm{m}$. 
Figure 3 - figure supplement 1

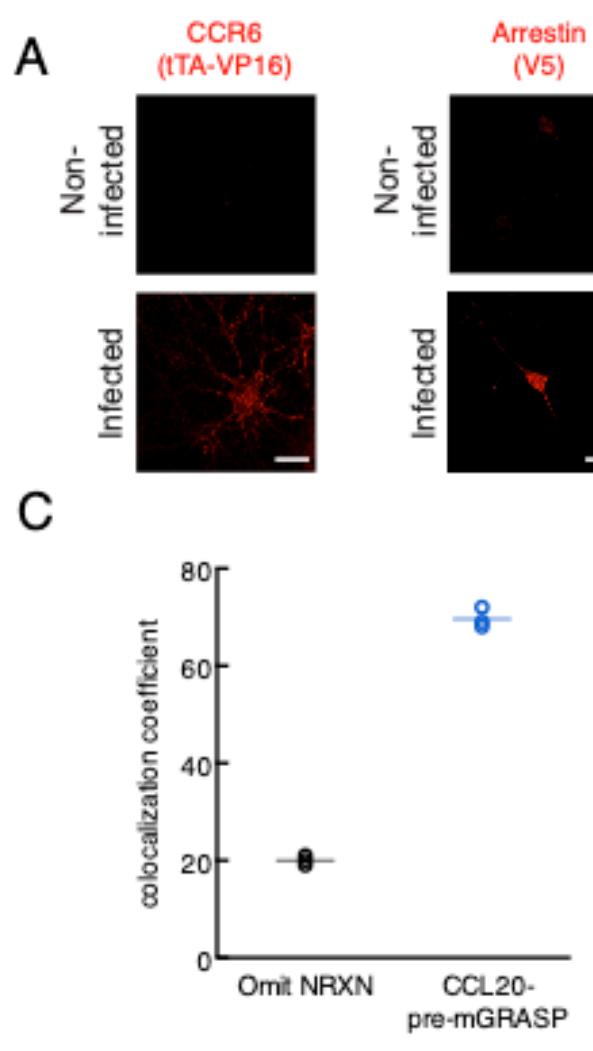

E

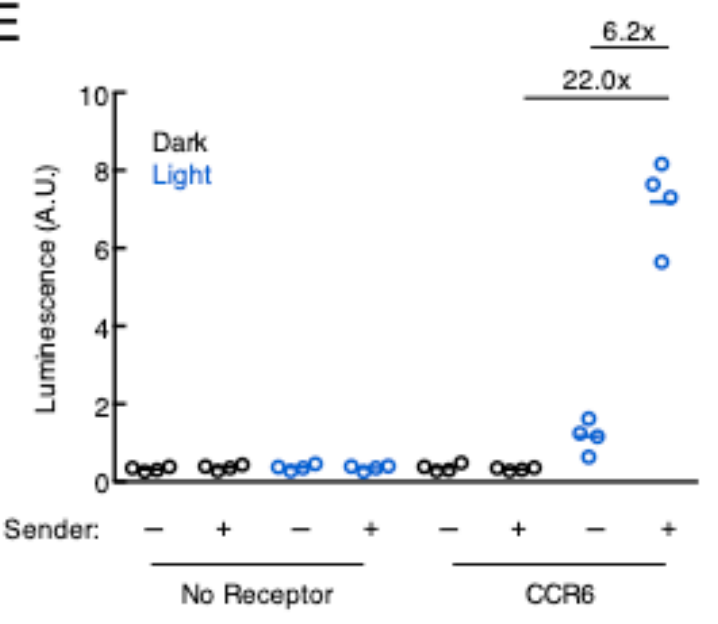

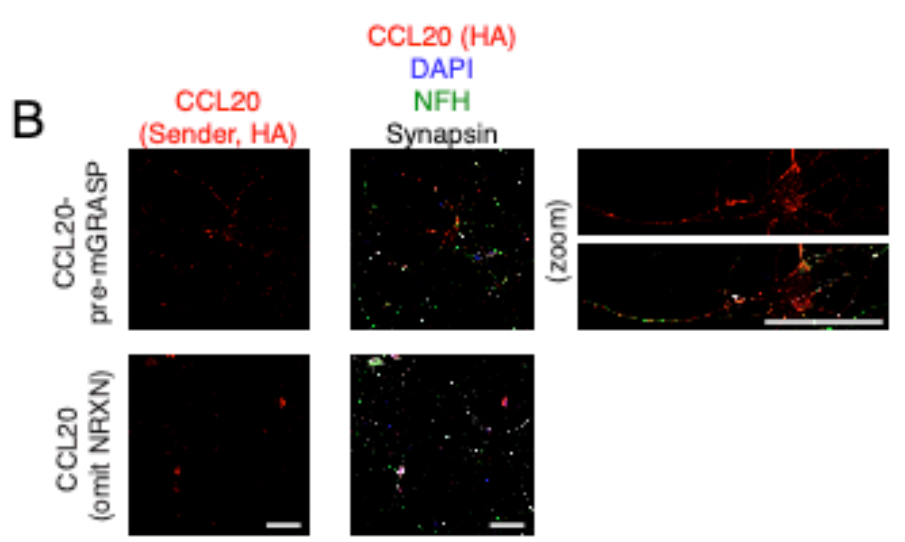

D

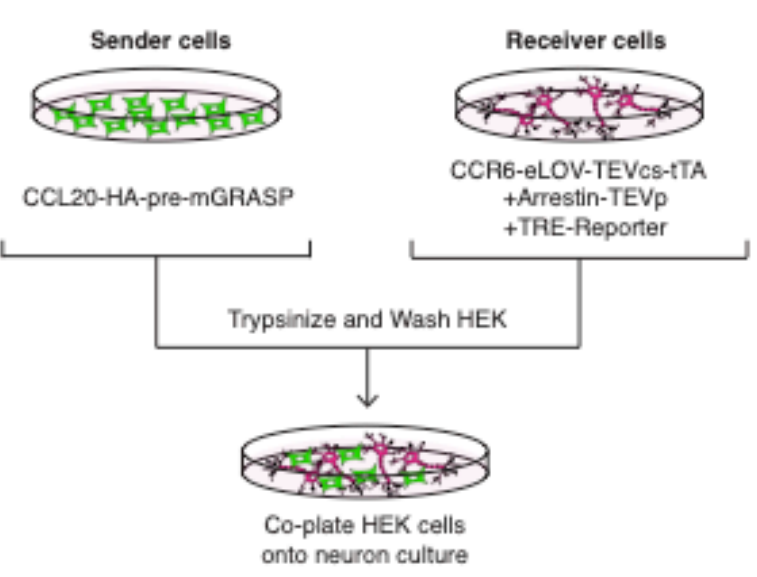

$\mathrm{F}$

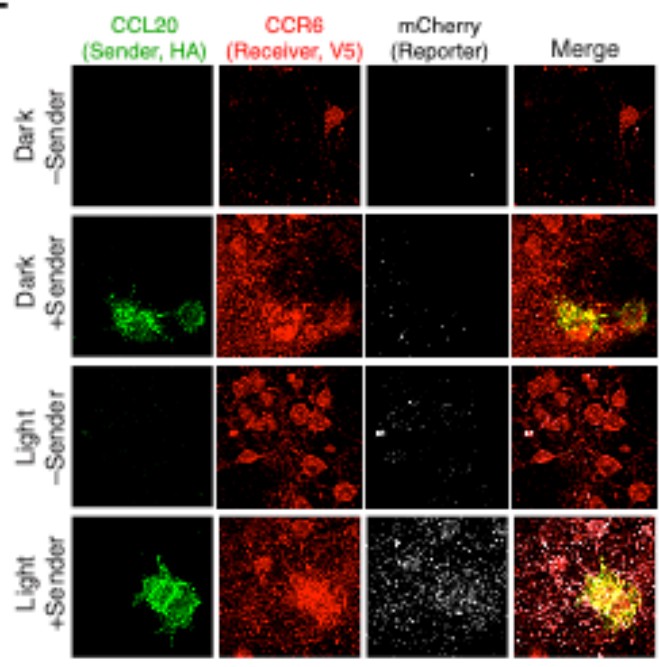

Figure 3 - figure supplement 1. Additional characterization of TRACC constructs in neuron

culture. (A) Confocal imaging of receiver constructs expressed in primary rat cortical neurons.

Neurons were fixed and immunostained with anti-VP16 and anti-V5 to detect the GPCR and 
arrestin components, respectively. Scale bars, $20 \mu \mathrm{m}$. (B) Confocal imaging of the CCL20 sender construct expressed in neuron culture. Neurons were fixed and immunostained with anti-HA to detect the CCL20 sender construct. Neurofilament (NFH) and synapsin were co-stained to visualize neurons and pre-synaptic terminals, respectively. A sender construct omitting the intracellular neurexin domain was included as a control. Scale bars, $20 \mu \mathrm{m}$. (C) Quantification of colocalization between HA (sender) and synapsin signals ( $\mathrm{n}=3 \mathrm{FOV}$ per condition). (D) Experimental design for co-plating receiver neurons and sender HEK293T cells. (E) Luciferase assay using receiver neurons co-cultured with sender HEK293T cells. Primary rat cortical neurons were infected with AAV1/2 viruses encoding the receiver constructs, using TRE-luciferase on DIV5. HEK293T cells expressing the sender construct were co-plated onto sender neurons on DIV9, and the resulting co-culture was light-stimulated on DIV10. Approximately 24 hours after 10 min. blue light exposure, the TRE-luciferase luminescence was recorded using a plate reader ( $\mathrm{n}=4$ replicates per condition). ( F) Confocal fluorescence imaging of sender HEK293T cells cocultured with receiver neurons, using TRE-mCherry. Cells were treated as in (E). Scale bars, 20 $\mu \mathrm{m}$. 
bioRxiv preprint doi: https://doi.org/10.1101/2022.02.22.481562; this version posted February 23, 2022. The copyright holder for this preprint (which was not certified by peer review) is the author/funder, who has granted bioRxiv a license to display the preprint in perpetuity. It is made available under aCC-BY-NC-ND 4.0 International license.

\section{Figure 4}

A

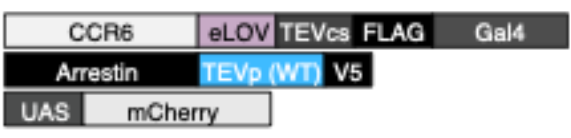

\begin{tabular}{|l|l|l|}
\hline CCR6 & eLOV TEVCS FLAG & Gal4 \\
\hline \multicolumn{2}{|c|}{ Arrestin } & UTEV1 V5 \\
\hline UAS & mCherry \\
\hline
\end{tabular}

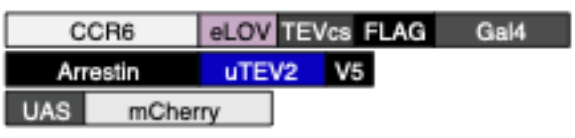

\begin{tabular}{|c|c|c|}
\hline CCR6 & hLOV TEVCS FLAG & Gal4 \\
\hline Arrestin & TEVP WT V5 \\
\hline UAS & mCherry \\
\hline
\end{tabular}

\begin{tabular}{|c|c|c|}
\hline CCR6 & hLOV TEV TS FLAG & Gal4 \\
\hline \multicolumn{2}{|c|}{ Arrestin } & UTEV1 V5 \\
\hline UAS & mCherry \\
\hline
\end{tabular}

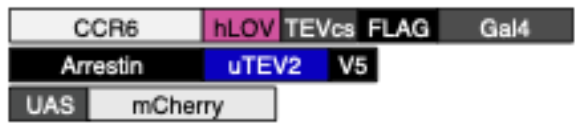
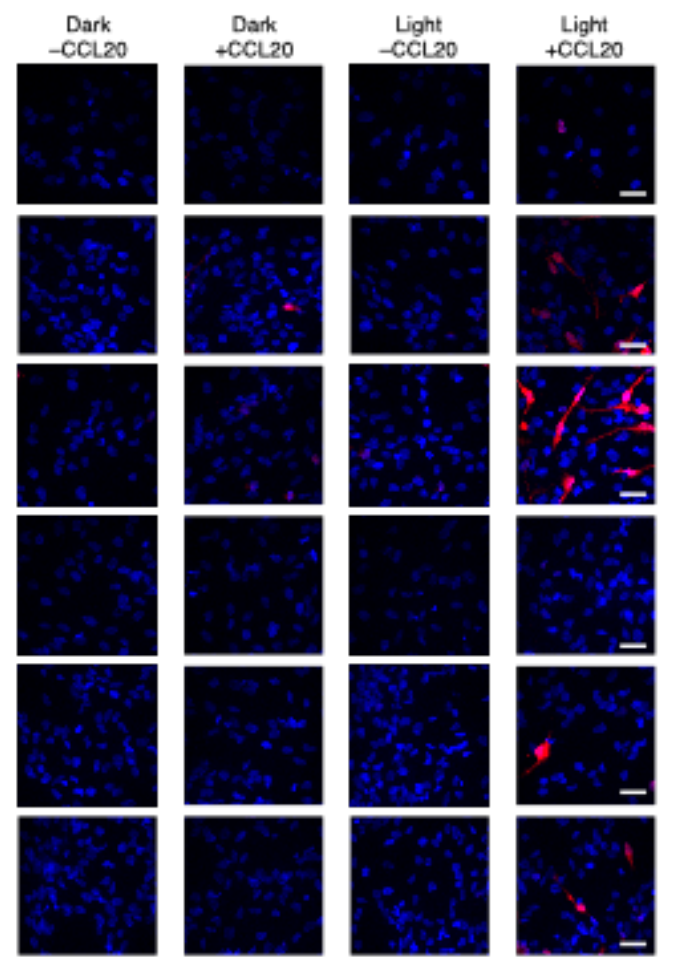

B

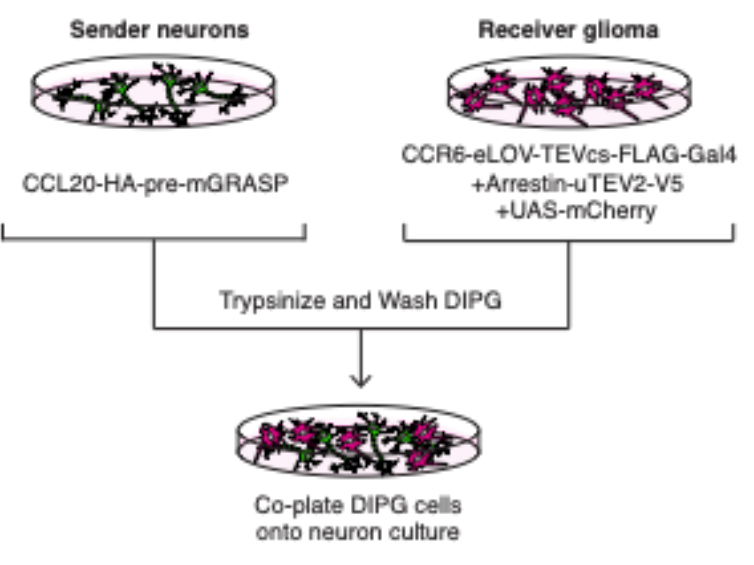

C
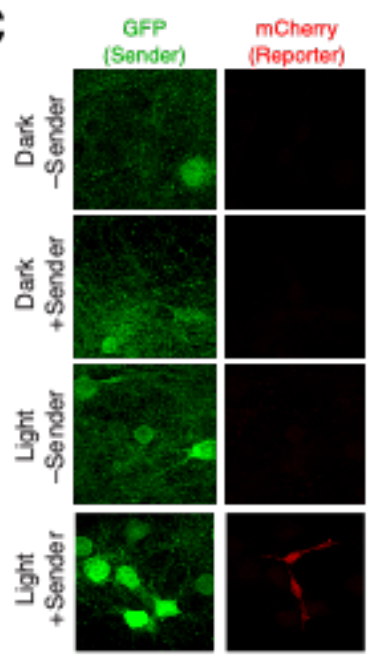

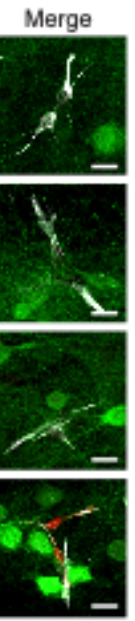




\section{Figure 4. Using TRACC to detect contacts in DIPG (diffuse intrinsic pontine glioma) culture.}

(A) Optimization of TRACC components in transposon-integrated SU-DIPG-VI stable cell lines.

We compared TRACC constructs containing eLOV or hLOV, and WT TEVp, uTEV1, or uTEV2.

Cells were plated and treated with $0.2 \mu \mathrm{g} / \mathrm{mL}$ recombinant CCL20 and $10 \mathrm{~min}$. blue light.

Approximately 24 hours after blue light exposure, cells were fixed and immunostained. Scale bar,

$30 \mu \mathrm{m} .(B)$ Experimental design for co-plating sender neurons and receiver DIPG cells. (C)

Confocal fluorescence imaging of DIPG glioma expressing receiver constructs containing eLOV

and uTEV2 co-plated with sender neurons. Primary rat cortical neurons were infected with AAV1/2 viruses encoding the sender construct on DIV5. DIPG cells were co-plated onto sender neurons on DIV9, and the resulting co-culture was light-stimulated on DIV11. Approximately 24 hours after 10 min. blue light exposure, cells were fixed and immunostained. GFP driven by the synapsin promoter was included as an infection marker to visualize transduced neurons; Nestin is a marker for DIPG cells. Scale bar, $20 \mu \mathrm{m}$. 


\section{Figure 4 - figure supplement 1}
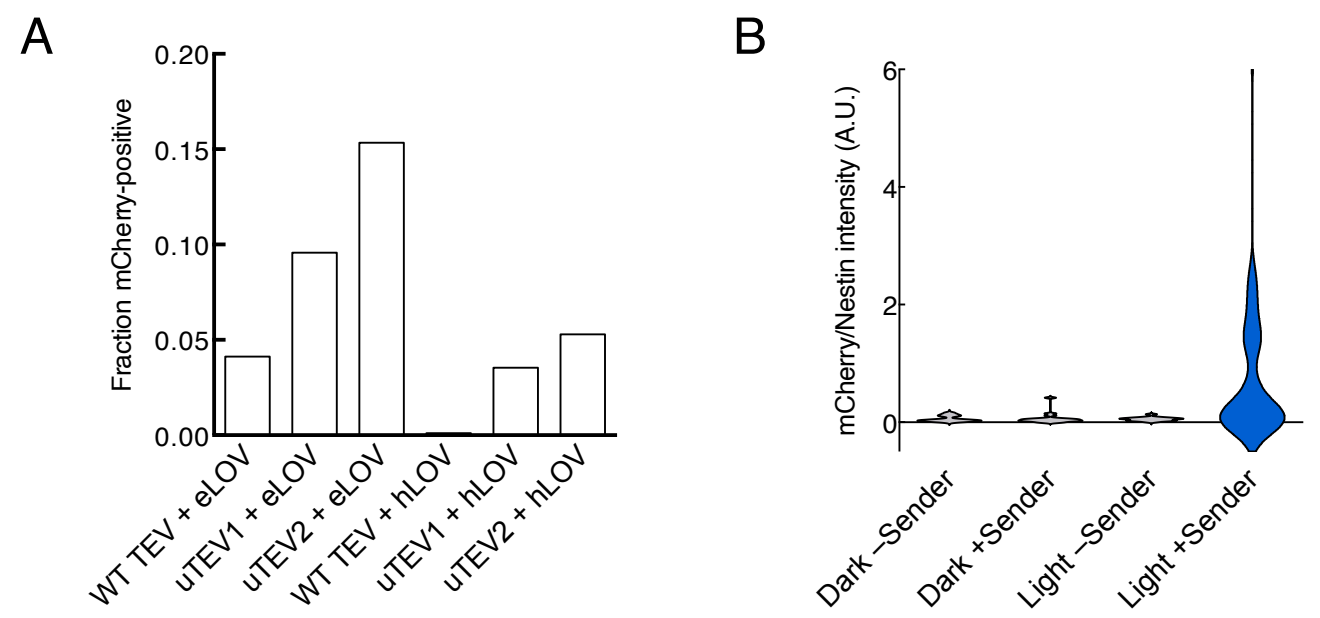

Figure 4 - figure supplement 1. Quantification of activation in DIPG stable lines. $(A)$

Quantification of mCherry activation upon recombinant CCL20 addition and light stimulation

for each transposon-integrated DIPG stable line. 97-208 cells were analyzed for each condition.

(B) Quantification of mCherry/Nestin intensity ratios for all Nestin positive DIPG cells in Figure

4C. 10-35 cells were analyzed for each condition. 